6-2011

\title{
A Historical Analysis of Attitudes Toward the Use of Calculators in Junior High and High School Math Classrooms in the United States Since 1975
}

Sarah Banks

Cedarville University

Follow this and additional works at: http://digitalcommons.cedarville.edu/education_theses

Part of the Science and Mathematics Education Commons

\section{Recommended Citation}

Banks, Sarah, "A Historical Analysis of Attitudes Toward the Use of Calculators in Junior High and High School Math Classrooms in the United States Since 1975" (2011). Master of Education Research Theses. 31.

http://digitalcommons.cedarville.edu/education_theses/31 
A HISTORICAL ANALYSIS OF ATTITUDES TOWARD

THE USE OF CALCULATORS IN JUNIOR HIGH AND HIGH SCHOOL MATH

CLASSROOMS IN THE UNITED STATES SINCE 1975

\author{
A thesis submitted in partial fulfillment \\ for the requirements of the degree \\ Masters of Education
}

By

SARAH A. BANKS

B.A. Integrated Mathematics Education, Cedarville University, 2008

2011

Cedarville University 


\section{CEDARVILLE UNIVERSITY \\ SCHOOL OF GRADUATE STUDIES}

June 28,2011

\section{HEARBY RECOMMEND THAT THE THESIS PREPARED UNDER MY}

SUPERVISION BY Sarah A. Banks ENTITLED A Historical Analysis of

Attitudes Toward the Use of Calculators in Junior High and High School Math

Classrooms in the United States since 1975 BE ACCEPTED IN PARTIAL

FULFILLMENT OF THE REQUIREMENTS FOR THE DEGREE OF Master of

Education.

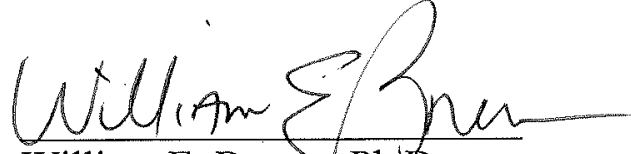

William E. Brown, Ph.D

President

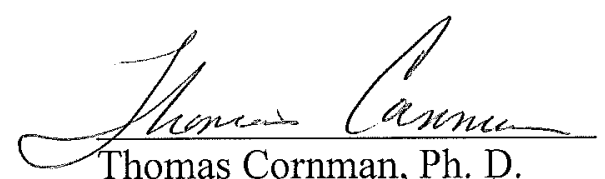

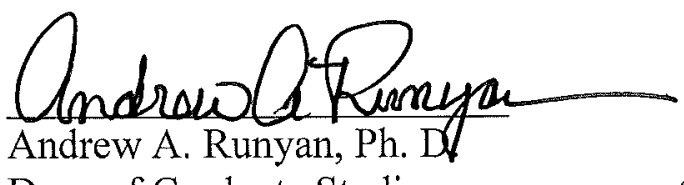

Dean of Graduate Studies

Stephen S. Gruber, Ed. D

Education Department Chair

Director M.Ed. Program

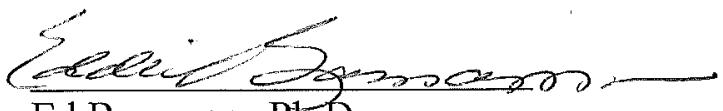

Ed Baumann, Ph.D.

Professor of Education

Thesis Advisor 


\begin{abstract}
Banks, Sarah A. M.Ed., Education Department, Cedarville University, 2011. A Historical Analysis of Attitudes Toward the Use of Calculators in Junior High and High School Math Classrooms in the United States Since 1975.
\end{abstract}

This thesis explored the history of calculator usage in mathematics classrooms in the United States since 1975 with a focus on the attitudes of parents, educators, and national organizations. The influence of historical events, people, organizations, research, and trends was explored in depth. Studying the changes that calculators have brought to mathematics curriculum and how educators have reacted in the past will help to explain why math curriculum and school systems have adopted the attitudes and policies about calculators that they currently hold. This study found similar attitudes and reactions by parents and educators toward calculator usage in contrast to the opinions and mandates of organizations such as the NCTM, the College Board, and local school board administrations. Parents and educators were strikingly more hesitant and concerned regarding the effects of calculators than educational institutions. The results will be useful for future curriculum decisions in mathematics classrooms. 


\section{Table of Contents}

Page

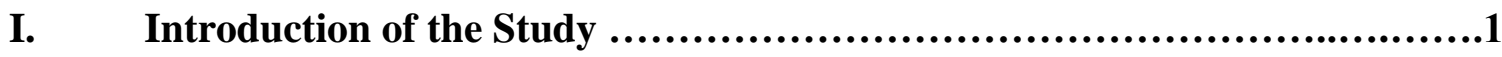

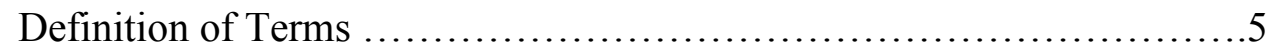

Statement of Problem .............................................. 6

Scope of the Study and Delimitations ..................................

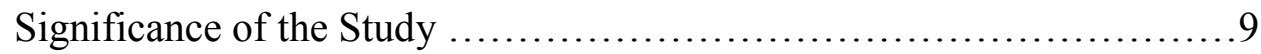

Methods of Procedure …...........................................10

II. Plenary Literature Review ..............................................12

III. Methodology ...........................................................49

Introduction to the Method ..........................................49

Rational for the Method..............................................50

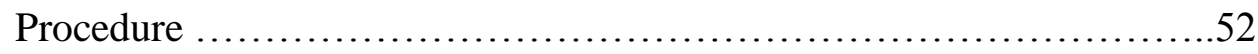

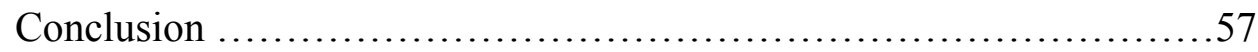

IV. Results and Analysis ....................................................58

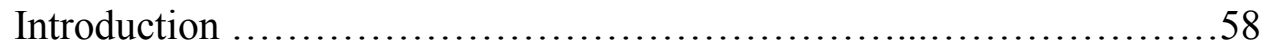

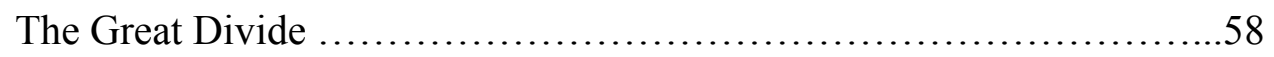

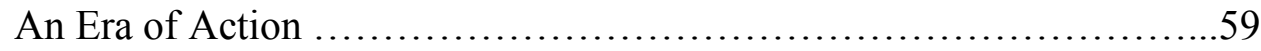

The Graphing Calculator Epoch ....................................61

A Strategic Decision ..............................................62

A Period of Confusion ............................................63

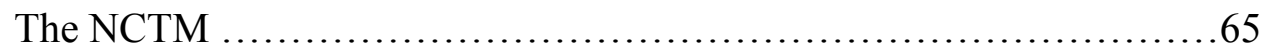


Educational Organizations ....................................... 70

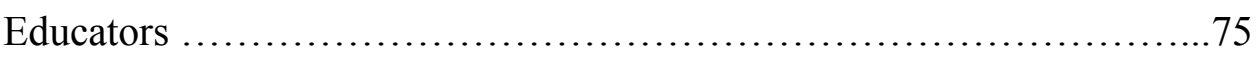

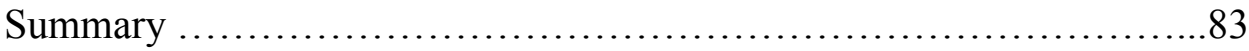

\section{Discussion and Implications}

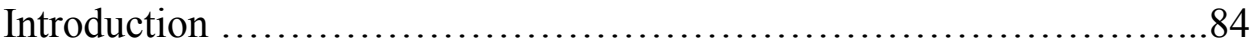

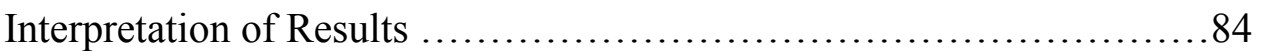

Potential Application of the Findings ....................................... 87

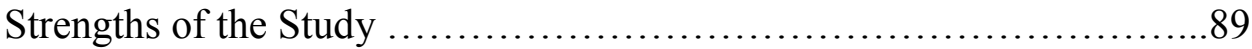

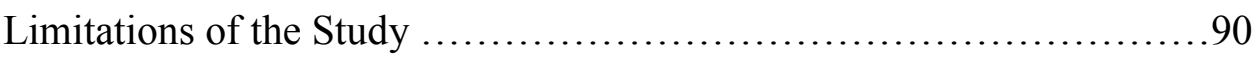

Suggestions for Future Research ...................................91

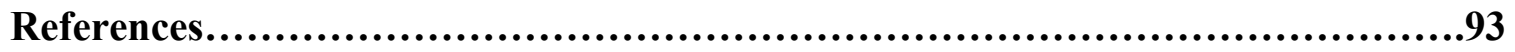




\section{Introduction to the Study}

Math class can be the dreaded hour of the school day for many children across the America. Students sometimes banter back and forth excuses for not finishing their homework or doing poorly on a test. Teachers often are plagued by questions of "why do we have to learn this?" and "am I ever going to use this in real life?" in between mutterings of complaints stating that class work is a waste of time. Teachers continually attempt to answer these questions while teaching content they believe is important, in addition to content deemed necessary by state and national standards. Is there a solution to the complaints of irrelevant mathematics by students?

The $20^{\text {th }}$ century ushered many possible remedies for teachers, students, and administrators alike in this regard. As one cogent example, the calculator emerged and quickly found its way into educational settings. But, was this new device successful? Did it solve student complaints or compound the problem by generating new concerns? Did this new technology simplify teaching strategies and encourage student exploration? Research throughout the past four decades has brought answers to some of these questions.

Calculating machines have existed for thousands of years, beginning with the abacus in Ancient Babylon (Gunstein \& Lipsey, 2001). This machine was not improved upon until the $17^{\text {th }}$ century when mechanical machines were able to add, subtract, multiply and divide (Gunstein \& Lipsey). The integrated circuit in 1958 moved society 
closer to the calculator currently in use. The 1970s resulted in the most salient change in calculator availability. By 1975 , pocket calculators were widely available due to their decreased price (Gunstein \& Lipsey). At this point, the easy access to calculators prominently began to affect the lives of average students and teachers.

The onset of calculators initially brought concerns that this new technology was not fully understood nor would be appropriately utilized by educators and that the effects on students were unknown. Future research studying how children were affected and the necessary changes to curriculum was recommended ("Math in the Schools," 1975). At this time, some educators feared that students would not be able to retain their knowledge of simple arithmetic if they learned to use a calculator before fully grasping basic mathematical concepts. Other teachers, however, saw calculators as a chance to increase student motivation by using more "real-life" problems (Pendelton, 1975).

This new wave of mathematical research was in full swing by 1980. Roberts (1980) analyzed and compared 34 studies of students, of all ages, searching for the influence that calculators were creating. He found computational benefits for most students, but did not see evidence that calculators were being used in a way that helped students advance their conceptual knowledge. Further concerns were stated as computers were being used for mathematics, but sometimes giving incorrect answers (Peterson, 1982). Was technology going to teach children wrong solutions?

A decade after calculators were widely used in mathematics classrooms, school administrators were forced to make decisions regarding calculators and standardized tests. During the 1985-1986 school year, the Connecticut State Board of Education became the first district to require calculators on state exams (Libov, 1986). However, 
this did not imply that all educators fully supported this new policy. Libov illustrated how dependency on calculators was still a popular fear among administrators.

Accepting the popularity of calculators and realizing that this tool was not going to disappear, educators were forced to adapt. At this point, teachers and curriculum writers searched for ways to teach effectively with the calculator as a pedagogical tool. Willoughby (1985) stated that students needed to understand how to use the calculators appropriately. Additionally, concerns arose that students had not been taught foundational skills such as estimation, in order to check the feasibility of the answers that their calculators provided.

Another milestone for students using calculators occurred as cities, such as Chicago, began to provide free calculators for all students ("Chicago Provides Free Calculators," 1988). Results of actions similar to this were mixed on the Iowa Test of Basic Skills. Students showed a gain in the area of conceptual knowledge. Many students also continued to perform well in the computational and problem solving portions of the test. Seventh grade students, however, did not do as well in the computational skills section ("Follow-up on the News," 1988).

A milestone event in the history of the use of calculators in math education was their allowance on the SAT (SAT, 2002). Scheuneman, Camara, Cascallar, Wendler, and Lawrence (2002), found that students who used calculators performed better on the SAT than did those who did not use them. The allowance was followed permission to use calculators on the ACT, Advanced Placement Calculus exams, National Assessment of Educational Progress, and other tests at the state and national level (Scheunemen et al., 2002). 
The graphing calculator, gaining popularity in the late 1990s, also began to reshape mathematics curriculum. Graphing calculators, now allowed on college entrance exams, were able to display graphs, tables, and solve equations (Wildstrom, 1997). With this novel technology came many new questions and concerns from educators. While graphing calculators tended to increase confidence and analytical thinking in students, they also pose potential problems for cheating (Lee, 1999). Critics of graphing calculators also emphasize that students need to be taught to understand math, not just plug numbers into their calculators and get an answer (Shapiro, 1999).

As calculators, specifically graphing calculators, became more prevalent in classrooms and permitted on standardized tests, concerns about equality were raised. The Educational Testing Service (ETS) allowed students to bring their own calculators, while other standardized testing organizations provided a standard calculator. Was this policy fair to students who could not afford the expensive calculators that other students were able to? Did this hinder their performance? Hanson, Brown, Levine, and Garcia (2001) reported that personal or standard issued calculators did not affect student performance.

As time wore on, research began to focus on math educators, specifically targeting teacher performance and use of calculators as a classroom tool. Laumakis and Herman (2007) completed a study with Florida teachers who received training on how to utilize graphing calculators in their own classrooms. The study showed an improvement in student scores against teachers who did not use this new technology. Within this study it is interesting to note that graphing calculators were not permitted on Florida state exams, the measuring stick of this study. Beyond the graphing calculator, new technology such as the TI-Navigator, allowed teachers to monitor student progress 
throughout math classes, instead of only at the end of a unit by a quiz or test (Cavanagh, 2006).

\section{Definition of Terms}

Abacus- a tool used to perform mathematical calculations by sliding counters along rods (Webster's Ninth New Collegiate Dictionary, 1988, p. 43).

ACT- Originally called America's College Testing Program, the name has been changed to ACT. It is an assessment for high school students' knowledge of English, mathematics, reading, and science to determine their ability to complete college level work (ACT, 2010).

Graphing calculators- a calculator with an electronic screen that allows students to graph, plot, compare, and analyze mathematical functions (Gunstein \& Lipsey, 2001).

NCTM- The National Council of Teachers of Mathematics is an organization and voice for mathematics education, encouraging the development of teachers and curriculum through current research (“Mission, Vision, and Priorities," 2009).

SAT- The Scholastic Aptitude Test is a national test in reading, writing, and mathematics used for admission into colleges and universities (SAT, 2002).

TI-83 Plus - a specific graphing calculator produced by Texas Instruments, allowed on college entrance exams and other state and nationwide tests ("TI-83 Plus: Features summary,” 2009).

ETS- Educational Testing Service is a nonprofit organization that administers, creates, and provides testing services worldwide. They administer and score tests 
including PRAXIS exams, the GRE, SAT, and Advanced Placement exams ("About ETS,” 2009).

NAEP- The National Assessment of Educational Progress is run by the Commissioner of Educational Statistics and administers tests nationwide with the purpose of determining academic progress over time ("NAEP Overview," 2009).

TI-Navigator- a graphing calculator with the capability to connect student calculators to a classroom computer in order to send problems and answers back and forth wirelessly (“TI-83 Plus: Features summary,” 2009).

\section{Statement of the Problem}

Without empirical studies of their use and effectiveness, educators are unable to aptly improve their teaching methodology and curriculum in order to provide a better education for students. However, research materials and studies alone were not what dictated current policies on calculator usage. In addition to research, it is the reactions and attitudes of classroom teachers, school principals, researchers, and curriculum developers that have also affected the quality and quantities of the tool's use in local school districts. This study will report results from the literature on the subjects of calculator usage and the reactions towards it use in education in order to form a cohesive history. The past four decades of research and experiences revolving around calculators in the math classroom have impacted school and society today; but how? The specific historical events that have influenced the present day have yet to be drawn together in a single, comprehensive study. This research will identify the key historical events that have influenced calculator usage in American junior high and high school math 
classrooms as well as the attitudes and reactions of educators that have impacted mathematics education today.

This review of literature lends itself to answer some important questions about calculator usage among junior high and high school math classrooms. This study will answer the following questions: what major historical events have changed how calculators are used in the classroom? Next, how have calculators affected classroom curriculum and teaching styles and what changes have educators made? Lastly, in response to these historical events and curriculum changes, how have teachers, parents, and educational organizations reacted and what effects have these reactions created? Each of these questions can be considered in light of a cohesive analysis of two major factors: the main historical events involving calculators in education and the reactions of educators, parents, and national educational organizations towards these events.

\section{Scope of the Study and Delimitations}

This study aims to identify the set of attitudes regarding calculator use in public junior high and high school math classrooms in the United States since 1975. The influence of historical events, people, organizations, research, and trends was explored in depth. This study reports historical trends of calculator use over the past four decades by separating the literature into periods of time marked by common themes. While trends are not completely linear, common themes of attitudes and views emerge through the data.

Limitations on the study have been chosen in order to focus on areas that have been substantially represented by literature from the past. As previously mentioned, 
calculators were first made available to the general public in mass quantity during the mid-1970s. It was not until calculators had become fairly inexpensive that parents and schools could afford to purchase the tool for children and general use. Thus, information about calculators in education before popular availability, that is before 1975 , was not included in this analysis of literature.

This study was also limited to research within public junior high and high school math classrooms. Public schools were chosen over private schools due to their more widespread use among families. Public schools historically have received more funding and grants for new technology in classrooms. This is particularly evident as schools began supplying calculators for all students in order to ensure equality. Many studies have also been conducted to follow up on the use of the calculators and their effects, once supplies were made available. Junior high and high school classrooms were also chosen because more research has been conducted on this age group. Researchers often use the terms middle school and junior high school synonymously. This study does as well. Research from sixth grade students and beyond was considered. By the junior high school level, students are more adept at using calculators and they are much more common in the classroom. Also, much research regarding calculator use centers around specific models of calculators, such as graphing calculators or the TI-83 Plus, that are used mostly by older students.

Research in other countries, outside of the United States, was not considered. Many of the attitude changes over time have been in response to organizations such as the NCTM or standardized tests such as the SAT. These tests and organizations are not 
present in other countries. Additionally, the same calculator models compared are not available worldwide.

The analysis of attitudes toward calculator usage focused on the perceptions and writings of researchers, educator, teachers, administrators, and other adults. Specifically, the attitudes of students and their own use of calculators were not considered. Research and other literature in educational journals and popular newsprint are from the adult point of view. These views tend to be founded in research and experience that is not available to a student learning to use a calculator in the math classroom. Teachers and researchers that have written this type of literature are able to articulate the background and motivation toward their attitudes about calculators.

\section{Significance of the Study}

Educators know that curriculum and teaching do not exist in a vacuum. Rather, they are continually impacted by students and the milieu in which they live. In order to prepare students for life outside of the classroom and potential societal contributions they may make, due consideration must be given to their respective environments. The world is continually changing and educators must serve as examples to students of how to either adapt to surroundings or change them. Calculators serve as one example of how a student's environment impacts educational achievement in significant ways.

In order to correctly respond to future changes, not only in educational realms, but all of our surrounding environments, it behooves educators to see a broader perspective. Looking back and seeing from where math education has come better helps to explain contemporary setting. Studying the changes that calculators have brought to 
mathematics curriculum and how educators have reacted in the past will help to explain why math curriculum and school systems have adopted the attitudes and policies about calculators that they currently hold. In order to better serve students and give them a high quality math education, math educators must better understand this piece of technology and how to use its future use potentially has been impacted by its past.

Math technology in schools will continue to develop forward. It is imperative to understand students' and teachers' current attitudes in order to react to changes in the future. This present analysis of historical shifts in attitudes will help form a cohesive history of calculators' past to help better make technology related decisions in the future. As history repeats itself, knowing history in this area will allow educators to further understand and grasp the next wave of technology affecting education. Toward that end, this present study will help critically analyze the risks and benefits associated with new technology as it is brought into math education classrooms.

\section{Methods of Procedure}

This study examined a full literature review of calculator usage in junior high and high school classrooms and the attitudes surrounding their usage since 1975. Available research databases including Academic Search Complete, MasterFILE Premier, ERIC, Education Full Text and Education Research Complete, PsychInfo, Professional Development Collection database, OhioLink, and Ebsco were utilized. These databases also pointed to full text articles at LexisNexis Academic.

These databases provided many peer-reviewed and scholarly studies. Additionally, many popular reading sources, such as the New York Times or Newsweek, 
were also included in the literature review. Non-research sources were necessary in order to examine the popular responses of teachers and administrators to published research. Additionally, these non-journal sources provided insight into the thinking toward changes in curriculum and educational policies of the day.

After all available research was gathered, it was read, classified, and analyzed for key points and trends from the last 35 years. Shifts in attitudes and calculator usage across various time periods were then identified. Next, common themes between eras of calculator usage were noted that connected different sources of research together.

Literature was then classified into five eras of time. Each time period is characterized by a change or shift in attitude toward the use of calculators in the classroom. Each period is also impacted by numerous organizations such as the NCTM or NAEP as they pushed for policies for or against calculator usage. However, as history and our responses towards it are never completely discrete, there is overlap between the defined eras. Teachers and administrators across the United Sates have not, and are not, always been in agreement on educational policies. A general overview of the noted time periods is also given. Lastly, there is a review of the attitudes of educators, parents, the NCTM, and other educational organizations and their specific changes in policy and reactions to calculator usage over time. 


\section{II: Plenary Literature Review}

The historical study of calculators in the Unites States is a relatively brief study. Research in this paper focuses on changes and attitudes towards calculators after 1975. However, a brief glimpse of their history before 1975 is a necessary basis for the study. Prior to 1975, calculator usage was rare, as they did not exist or were not readily available. However, once their usage was more widespread, changes seemed endless.

The study of mathematics has changed greatly over time. These changes were aided by both theoretical and technological advances. The abacus was the first device used for calculating. It was invented thousands of years ago and remained useful until 1642 when the first mechanical calculator was invented (Gunstein \& Lipsey, 2001). In 1671, a calculator that could complete addition, subtraction, multiplication, division, and square root problems was developed. The invention of the integrated circuit in 1958 began the modern era of calculators, as it now had a memory to store numbers and algorithms (Gunstein \& Lipsey).

The first widely available calculators were produced in the mid-1970s and were affordable for most Americans (Gunstein \& Lipsey). They were also called mini-calculators at this early stage. The National Advisory Committee on Mathematics Education (NACOME) created an overview of mathematics education prior to 1975 (Conference Board of the Mathematical Sciences, 1975). Their report included the initial impact that calculators had on math education and their future predictions of the implications of calculators. Though calculators and computers were rampant in government, business, and industrial spheres, they were not utilized by the field of education. Yet, students knew that calculators were available and had trouble understanding why they weren't allowed to use them in school. The committee foresaw 
an increase in use of calculators by students as the price of a calculator used in high schools or capable of doing collegiate math cost less than $\$ 50$ (Conference Board of the Mathematical Sciences). The committee predicted a number of changes that needed to occur for educational success including the change of instructional priorities, earlier introduction of decimals, exponents, square roots, and other calculator functions, in addition to helping students understand how to use the calculator as a tool in problem solving (Conference Board of the Mathematical Sciences). Additionally, they believed that fractions would not need to be taught at an early age anymore, because calculators use decimals instead of fractions. The Conference Board of Mathematical Sciences also recommended that students who struggle to learn mathematics use a calculator for assistance instead of being stuck on computational drills and developing negative attitudes. The 1975 study by NACOME also recommended that all students in eighth grade and above have access to hand calculators for all class work and tests (Math in the schools: What's wrong?, 1975).

This recommendation was already well on its way. In 1975, there was already one calculator for every nine Americans (Pendelton, 1975). Educators insisting on calculator usage in the classroom focused on the benefits of increased motivation and desire to learn from students as reasons to utilize these new devices. Most believed that students should be taught the basics before being allowed to use a calculator, in hopes that students would understand how their calculator generated the answer (Pendelton). Teaching a student basic skills and then allowing them to use a calculator on more realistic problems with bigger numbers was stated to improve interest and motivation because more relevant problems were solved (Pendelton).

However, other educators were skeptical to fill classrooms with calculators whose effects had not been thoroughly researched. At this point, little research had been done on student use 
of calculators ("Math in the schools: What's wrong?"). Educators foresaw curriculum changes, such as teaching estimation principles, which would need to be put in place first. This would help students determine the validity of the calculator's answer (Pendelton). A survey done by Mathematics Teacher found that $72 \%$ of teachers, mathematicians, and laymen did not want $7^{\text {th }}$ grade students to be given calculators for use in their math classrooms. Critics feared that students would no longer be able to do basic math without the assistance of a calculator. Some teachers chose to ban calculators from their classroom altogether (Pendelton).

One of the earliest research studies on the connection between calculators, achievement, and parental attitudes was conducted by Rudnick and Krulik (1976) who studied 600 seventh grade students and their parents for an entire year. The initial concerns of parents included the beliefs that calculators would impair students' abilities to complete paper and pencil tasks, that their children would become dependent on the calculator, and that students would forget how to do math once they used the minicalculator. The pre-test, post-test design on the students' use of calculators revealed that students' learning was not hindered in their mathematics education or in their paper and pencil calculations. At the end of the study, parents continued to have strong reservations for allowing calculators into the classroom. They shared their main concern: their children would become dependent on the technology and forget basic skills. They continued to fear that their children would not be able to do basic mathematics. Parents did believe that calculators would improve student attitudes in math class, but not for school in general. Half of the parents, however, did want their students being taught how to use calculators. The basic guideline from parents was that students should be taught how to use the minicalculator, but not be permitted to use it until they had mastered basic skills (Rudnick \& Krulik). 
In 1976, Vaughn published a research study that focused on the effectiveness of calculators in regards to achievement, retention, and student attitudes. Vaughn's research was designed to give instruction to teachers who were unsure if calculators would help or harm their students' learning. At this point in history, very little research had been conducted to test the usefulness of calculators in the classroom (Vaughn). He concluded that these ninth grade students had a higher level of mathematical achievement when using a hand held calculator. Note that the curriculum for the students using calculators was adjusted to fit in this new technology. From this, Vaughn recommended that teachers be trained how to best utilize calculators in their classrooms to be most effective. Vaughn, however, did not find significant results in regards to a change in students' attitudes or retention of skills.

In a summary of the early research of effects of the minicalculator, Quinn (1976) studied both sides of the calculator debate. Proponents of the calculator believed that it increased student attitudes and interest, was easily used by students of all ages, and allowed students to maintain computational skills. Also, for students to use a calculator, they must first know how to process or translate a problem in their mind to understand it first, before using a calculator. Proponents of calculators used this to claim that the method of calculation does not matter, because students understand the concept and process behind the mathematics. Critics of the calculators feared that students would not be able to compute mentally or with a pencil and paper as they became dependent on the machine (Quinn). To date, research had proven five main points. "Students: (a) learn to operate calculators easily at almost any grade level, (b) compute better with calculators than without, (c) are able to tackle more "real-life" problems, (d) suffer no loss in paper-and-pencil computational ability, and (e) enjoy using calculators." (Quinn, p. 79). Quinn notes that conclusions are difficult to draw at this point, because many 
studies lasted less than a year. This length of time was inadequate to study the long-term effects of calculator usage on students.

In 1978, The National Council of Teachers of Mathematics (NCTM) released an official statement of their opinion of the use of calculators (Taylor \& McKean, 1979). Their position advocated for the use of calculators to increase during instruction and generate new opportunities for students to solve modern-day problems. The statement also noted that calculator usage could have the additional benefit of improving students' attitudes toward mathematics, but was clear that calculators should not replace a students' learning of computation (Taylor \& McKean).

Review of the 1977-1978 National Assessment of Educational Progress (NAEP) mathematics assessment provided insight into our math classrooms by determining what students were learning and what students needed to learn. Noticing that American students needed better computational competency in the future, directives to use calculators to improve these skills were given (Suydam, 1982).

Research also done in the 1970s found that a student's attitude toward mathematics was related to their achievement (Laursen, 1978). Laursen studied the addition of calculators into the classroom and the resulting change in student attitudes. Her study concluded that the use of calculators did increase achievement, but the attitudes of the students did not change. This early research did not include the attitudes of the teachers (Laursen).

Though the benefits of the calculator were clear to some, others continued to fear that students would no longer be able to do simple arithmetic or other operations without the new machine (Kiehl \& Harper, 1979). Another concern regarded the possibility of errors. Students were unable to see computational errors that were made because the calculator did not keep a 
copy of the student's work and entries. In the same vein, teachers could not see where students were making mistakes in order to help correct them (Kiehl \& Harper). Yet, continued benefits of quicker calculations, ability to spend more time solving problems instead of being bogged down by computational problems, and higher student motivation were observed. Educators were able to sense that the calculator was going to be a part of their students' future and it needed to be taught and utilized properly at school (Kiehl \& Harper).

Though research was done in the mid to late 1970s, it did not appear that classroom teachers heard the results from the research or actively engaged them. Wyatt, Rybolt, Reys, and Bestgen (1979) completed a study of 10 school districts and their use of calculators. Of the teachers that were interviewed, $84 \%$ believed that calculators should be used in schools (Wyatt et al.). However, only $3 \%$ of these teachers stated that their schools had made calculators available to them. They mentioned concerns over not having enough training, if any, to successfully teach with them. Teachers needed help from administrators and support from parents to begin utilizing this technology in their classroom. None of the districts had policies on calculator usage. Teachers were afraid that students would forget basic computation skills. They agreed that students needed to master a skill or concept first, before being shown how to use a calculator to solve it. Additionally, they would need updated curriculum to adjust to these new changes (Wyatt et al.).

The NCTM's Agenda for Action (1980) emphasized the importance of schools providing calculators and computers to mathematics classrooms in order to fully integrate calculators into teaching. In addition, calculators were not to be used to check work, but for exploration and discovery learning. The NCTM emphasized their importance in the area of problem solving. When the task of computation becomes too great for a student and educational 
value will not be added by doing a computation by hand, the calculator should be used. At this point, the NCTM recommended 12 actions for educators in regards to computers and calculators. Foremost was their sanction that all students have access to calculators for the entirety of their mathematics education. Other calculator recommendations included the integration of calculators into mathematics curriculum, the use of calculators in untraditional and varied manners, and teacher interactions with parents to increase calculator usage at home to achieve greater benefits at school.

Seitz and Parks (1982) found that virtually every student had access to a calculator at home and concluded that teachers and schools must form their reaction to this fact. To ignore calculators in school would be to disregard new technology and seem hypocritical to students. Since students had access to calculators at home, teachers had an increased responsibility to determine guidelines for using calculators in the classroom, in addition to homework. At this time, teachers were extremely divided over the role of calculators in the classroom. Those who did not use calculators felt that the acquisition of computational skills would be hindered through calculator usage. Teachers who were firm believers in incorporating this new technology into curriculum felt that calculators were a necessary tool of the future. Additionally, calculators were beneficial for students that were active learners. The calculator gave students more control of their learning. This new technology was also to be used to help students discover relationships, reinforce concepts, check their own work, and solve many real life problems (Seitz \& Parks).

Roberts (1980) reviewed 34 studies focusing on the effects of calculators on students' achievement and attitudes in mathematics. In the classrooms studied, he found $47 \%$ of students were not allowed to use calculators on assessment at that time, even if they were permissible 
during periods of instruction. Teachers and schools had yet to create policies for these situations. In his research of secondary students, there was strong evidence to support the effectiveness of calculators in increasing computational benefits for students. Greater benefits were attained when students were allowed to use the calculators during instruction and on tests as opposed to only during instruction time. Yet, evidence promoting improvement in conceptual thought or attitudes was not attained. No difference was found in student understanding if they used a calculator or not. An additional benefit of calculator usage was that students were able to complete more problems in a set amount of time. However, it was unclear if this extra practice helped students grasp the concept better. Lastly, Roberts also noted that no research had been conducted yet of the best time to introduce the calculator to students.

Gary Bitter (1980) studied teachers' attitudes toward calculators in their classrooms. Upon first surveying the teachers, Bitter found that teachers of the middle school grades had more favorable attitudes toward calculators than teachers of both younger and higher grades. Then, after gathering initial data, 84 teachers attended a two hour, hands on, workshop that taught them how to use the pocket calculator in their classroom with specific instruction, topics, and activities. After the workshop, teacher attitudes were measured again. This time a significant gain in favorable attitudes by all teachers was found. The workshop had a direct impact on the change of teacher attitudes. Bitter concludes that in order for calculator usage to be more prevalent in schools, teachers need to be trained how to use them effectively in regards to instruction and application.

The NCTM continued to push for greater use of calculators for all students so that each student would be technologically prepared for the future, whatever their career might be. 
In addition to higher utilization of calculators, the organization also continued to push for higher requirements in mathematics for graduation ("Mathematics teachers urge course reform," 1980).

Former NCTM President Stephen Willoughby's (1985) main concern regarding students and calculators was a fear that students would forget how to think on their own or solve simple problems without their pocket calculator. He emphasized making and teaching connections between math and the world that we live in, in order to challenge students to solve problems with the calculator as a mere tool. Equally important, Willoughby wanted students to use good judgment when using calculators and to realize that calculators can only compute what humans have created them to do. Estimation was a skill that continued to need emphasis if students were going to continue to use calculators in class. If students were taught how to use a calculator, they would be able to solve problems that interest them confidently. Children needed to be taught how to use calculators effectively and utilize their full capabilities (Willoughby).

In 1986, Connecticut was the first school to require the calculator on a state mandated test (Libov, 1986). 35,000 eighth grade students also received a calculator at the beginning of the year. Teachers had also been instructed on how to teach the students how to use the calculators on the state test. The Connecticut School Board cited many reasons for the passing of this mandate. Members stated the benefits in their defense of the decision. The use of calculators would allow students to spend more time solving complex problems, improving their mathematical skills, and increasing focus on estimation (Libov, 1985). However, other members were concerned that the fundamentals of math would not be taught as well, students would not think clearly about estimation, and that they would rely too heavily on this tool (Libov, 1986).

George Immerzeel (1986) shared his success with using calculators in his classroom as a motivation for others to join in. He felt that allowing his students to first explore with 
calculators would create increased student interest and ownership for their learning. He also admitted that the calculator made teaching easier for him (Immerzeel). His students generated their own real life problems that they were curious about and saved time solving them with the calculator. They also transferred their specific learning to more generalized concepts by using this handheld technology. In addition, students realized, on their own, the benefits of knowing basic math facts and skills instead of using the calculator. These benefits led Immerzeel to reflect on changes that needed to be made in instruction. Teachers needed to teach students to record what they are doing on the calculator as well as the steps that led them to the answer. Additionally, students needed further instruction and help with the topic of estimation (Immerzeel).

As calculators were being mandated in schools, parents were anxious for their children. Concerned father, Erik Sandberg-Diment (1986) was hesitant to buy a calculator for his daughter fearing that she would begin to lose her conceptual skills and become dependent on the machine. He insisted that without the practice of mentally solving problems it is difficult to know if the calculator answer is correct. Without practice, a student's minds would not intuitively know when an answer seems correct or not (Sandberg-Diment).

As students began to take more complex classes in high school and use calculators throughout their education, college professors began to notice that the classic, first college class, Calculus, needed to change (Gleick, 1987). Current Calculus textbooks and teaching methods were not staying up to date with the advances in technology, specifically the hand held calculator. As more and more students were bringing these devices to college with them, the course seemed inadequate. Calculators could do most of the work for the student. Although the exact direction that new Calculus classes needed to go was not fully understood, agreement was 
made that a change was necessary (Gleick). University of Arizona mathematician Deborah Hughes Hallett agreed with the need for curriculum reform (Clayton, 1999). She did not call for the dismissal of calculators, but rather advocated to show students the concept at hand first, and then how to solve it with the use of calculators so that students saw the importance of both. She was also concerned that students will question why it is necessary to learn math at all or quit asking why concepts actually work, if they have a calculator that simply give them the right answer (Clayton).

McConnell (1988) cited reasons that teachers did not fully embrace teaching with technology. He summarized the teachers' main reasons as: the non-allowance of calculators on the ACT or SAT, the lack of algebraic knowledge that students will gain, the hindrance of future studies of mathematics due to reliance on calculators, the need to wait for conclusive evidence of how technology affects future curriculum and textbooks, and the lack of classroom computers (McConnell). However, McConnell disagreed with these teachers. He argued that calculators are could be found far and wide and should not be dismissed. At this time, four function calculators were available everywhere and the cost of scientific calculators was minimal, even if the school were to provide them for all students (McConnell). He saw many benefits to using calculators that were being ignored by teachers. He claimed that the definite place in teaching algebra that calculators have was being ignored. He also stated that students would have a much better visual concept of functions if they were permitted to use a calculator. This would help them for many years in the future of their mathematics education.

The NCTM's Principles and Standards for School Mathematics (1989) outlined the pending changes in the mathematics education community. One of the major reasons for reform was the shift of the United States from an industrial country to an informational society. The 
availability of calculators was but one reason for the change in society yet it necessitated a change in mathematics education (NCTM, 1989). The goal of the standards is to ensure that high school students have a strong understanding of mathematics and are able to use these skills out in the real world ("Math Standards" Education Digest, 1989). One of the major results of this emerging technology was the belief that students should have access to calculators all of the time (NCTM, 1989). The NCTM wanted students to know how to solve problems in a variety of ways, including using the calculator as a tool. However, one of the assumptions in the NCTM's standards was that students had access to calculators with graphing capabilities all of the time. Many of the content standards were connected to the use of these devices. The NCTM likened new mathematics classrooms with calculators and computer software to science classrooms or laboratories. Students should discover, make conjectures, and determine their correctness in mathematics curriculum as well. The organization also cites another advantage of increased calculator use will be improved student interest, stimulating classroom environments, and higher student self-concept (NCTM, 1989).

Bitter and Hatfield coordinated a two year study that began in 1988 with the integration of the Texas Instruments Math Explorer Calculator into the mathematics curriculum for 580 seventh- and eighth-grade students (1993). This calculator was designed for use in middle schools. Their study ensured that each student had same calculator to use at school and at home in addition to training teachers how to incorporate this new technology into their curriculum. They began under the premise that the calculator is a necessary tool for students today and that it should be incorporated into mathematics curriculum in order to raise the level of student thinking, problem solving, and critical thinking (Bitter \& Hatfield). 
At the end of the study, the attitudes of students, parents, and teachers were assessed. The parent questionnaire revealed four major findings. First, after seeing their child use the calculator over the course of the school year, parents had a positive view of it. In addition, $90 \%$ of parents wanted the calculator to be standard part of the mathematics curriculum. Next, only $12 \%$ of the parents did not believe that the calculator was beneficial for helping their student solve problems involving fractions. And, $40 \%$ of parents believed that calculator usage would hinder their child's computational skills (Bitter \& Hatfield).

Teachers also had a favorable attitude toward the use of this calculator in their curriculum. From the beginning of the study to the end, teachers' attitudes increased by $20 \%$. All of the teachers involved agreed that that it should be a normal part of their classroom. Also, teachers unanimously agreed that calculators made math more fun for their students. (Bitter \& Hatfield).

In 1988, Chicago Public Schools gave out a free calculator to every student, beginning in the fourth grade ("Chicago Provides Free Calculators to Students," 1988). The aim was for students to spend less time doing calculations by hand and more time alleviating the fear of math and solving more complex and challenging problems. Yet one vocal dissenter claimed that the calculator would cause lasting damage to student learning. Teachers still required the memorization of multiplication facts and tested them without the use of a calculator ("Chicago Provides Free Calculators to Students"). Testing results that same year were mixed ("Free Calculators For Chicago Pupils," 1988). Students either met or exceeded the national norms in the areas of problem solving and computation, except in seventh grade ("Follow Up On The News: Free Calculators For Chicago Pupils"). 
A portion of the Iowa Tests of Educational Development is devoted to testing a student's ability to problem solve (Ansley, Spratt, \& Robert, 1989). The test was given to two groups of students: one group with calculators and the other group with pencils and paper. There were about 95 students in each group. Students in the calculator group were given a four function calculator. Then, 25 questions from the two part test were selected and analyzed. The calculator group performed slightly better on both portions of the test: items requiring computation and items not requiring computation (Ansley et al.). However, the results were not significant and showed that the use of a calculator did not prove to be advantageous. There was no difference in regard to gender. The results also showed that the calculator group took an extra two minutes to complete the test when compared to the non-calculator group. It also suggested that male students worked faster than female students. Researchers believe that the extra time spent on the test by those with calculators was spent testing the other possible given answers on their calculators (Ansley et al.).

In 1989, The National Research Council published Everybody Counts: A Report to the Nation on the Future of Mathematics. The book emphasized the importance of a solid mathematics curriculum for both students and the growth of our nation. It specified that quality mathematics education cannot be overstated. The report also noted the importance of computers and calculators to teaching students, but observed that as a whole, the educational society had steered away from using them. One of the greatest challenges facing mathematics education at this time was that calculators were not impacting the classroom despite their benefits. The Research Council believed that calculators should be used in the classroom for a number of reasons. First, calculators make math faster and promote exploration. They also motivate students who struggle in math to move father along the mathematics track as they use the 
calculator as a tool. Additionally, students can use realistic data and explore their own curiosities. The Research Council also predicted that current textbooks will be quickly outdated and teachers will need to change their approach to instruction in order to adapt to the use of this new technology (National Research Council, 1989).

During this time of transformation in the field of mathematics education, change was not easily accepted by all (Bright, Lamphere, and Usnick, 1992). The two main obstacles to using calculators in the math classroom involved parents, administrators and teachers. The first difficulty was convincing adults that calculators enhance education and help children problem solve, instead of believing the assumption that calculators are only used for simple computations. The second problem with calculator incorporation was training teachers how to most effectively utilize the technology in the classroom in appropriate and beneficial ways (Bright et al.).

While some administrators and parents have had a difficult time adapting to change, high school teacher Joseph Mercer (1992) quickly changed his philosophy of teaching to not only include calculators, but make them the foundation for his teaching. He believed that forcing students to learn the basic skills of math by hand through repetition is detrimental to their growth as mathematicians. He also felt that teaching mechanical skills is unnecessary as they will not be useful to students in the future. He promoted the process of starting to teach to young children with calculators and then come back and work through analytical skills. He believed that students should understand that math is about thinking logically and communicating it, not memorization or systematic algorithms. If students are taught to learn in this way, Mercer claimed that basic skills and the learning of algorithms would come naturally. He believed that teachers need to reevaluate what is truly important. If teachers teach with calculators, students 
will begin to wonder how the calculator found the answer and then teachers will have opportunities to teach mechanical skills (Mercer).

Barrett and Goebel (1990) predicted that graphing calculators would soon be available to all students. But, if students were unable to afford one, they believed that schools should provide a classroom set to allow teachers to fully utilize the technology in their classrooms. They foresaw the three main areas of mathematics that will benefit most from the new technology: solving equations, analyzing functions, and data analysis. Previous to the use of graphing calculators, data analysis was basically void in high school curriculums. These researchers felt that graphing calculators would give teachers greater opportunities to teach techniques for solving equations than before and allow for the use more realistic example problems. In order to analyze functions, teachers needed to spend more time teaching the concepts of domain and range so that students will be able to graph functions on their calculators and analyze them with greater accuracy. Ultimately, Barrett and Goebel believed that the graphing calculator would bring greater enthusiasm to the classroom, better understanding, and student recognition of the power of math in real life situations.

Calculators continued to develop and became more advanced. In the 1990s, graphing calculators were a common item in mathematics classrooms. Teachers integrated this new technology into the curriculum utilizing its capacity to give remainders in division, convert rectangular to polar graphs, dual graphing screens, and even store and print data (Gunstein \& Lipsey, 1991). Graphing calculators had been cumbersome to work with at their inception, but by 1991 their lightweight model and easy to use features allowed for widespread use among students. Researchers claimed that these calculators were the wave of the future (Trotter, 1991). They were easy to use for both students and teachers with training. They predicted that students 
would more readily make mathematic connections because they did not have to make graphs by hand anymore. Teachers were also excited about this new opportunity, but needed training to use them well (Trotter).

With the rise in popularity of graphing calculators, teachers needed guidelines to understand how to best use the technology their students were embracing (Burrill, 1992). Burrill suggested that the answers are not easy, but would be discovered over time and with patience in trying new activities (Burrill, p. 22). He also encouraged the use of a graphing calculator to introduce a new idea or technique to students (Burrill, p.19).

Walter Ryan (1992) studied the effect of TI-92 calculators used in Geometry classrooms on student attitudes. He found that using this technology generated very positive attitudes from students in addition to higher test scores. Possible factors contributing to higher student attitudes may include ease of visualization, cooperative work, and the novelty of using new technology (Ryan).

As graphing calculators became more popular, middle school teachers began to integrate them into their own classes, instead of waiting for students to move on to high school. Taylor and Nichols (1994) designed activities specifically for middle school students to explore and learn with graphing calculators. They observed that students enjoyed the activities and appeared more confident in the skills as mathematics students when using them. They emphasized that their students had a good understanding of the mathematical concept before using the graphing calculators. Students were able to use the calculators to solve problems of distance and rate, population, and maximizing volume by involving the creation of tables of values, equations, and graphs. Students understood the relationships between these three key 
elements. According to Taylor and Nichols, these activities enriched student understanding and appreciation for mathematics while deepening their algebra skills.

Negative opinions of calculators continued to surface and become more vocalized as calculators were now required on part of the New York's Regents exam (Klutch, 1991). Opponents of the calculator stated that school is a place to learn how to solve problems, not simply get the right answers. As a teacher, Klutch believes that calculators are the easy way out and do not teach students how to solve problems on their own. Students lacked number sense skills. He was particularly upset that calculators are being used by younger and younger students each year (Klutch). The following year, the New York State Education Department allowed calculators to be used on the entire Regents' exam and students were no longer required to show their work. When New Jersey enacted the same policy, they spent $\$ 1.5$ million on calculators (Calculators Allowed For Math Regents).

Stephen Willoughby (1992) shares additional concerns that calculators seem to be a secretive device that tells people how to do math. He emphasizes the importance of teaching students the necessity of mathematical conventions, such as order of operations; so, that they know how calculators arrive at a particular answer and that the answer makes sense. Students need to be shown and allowed to discover on their own why mathematical conventions and ways of thinking are necessary. Students need to believe that math is important rather than something to be learned because adults say they need to. He reiterated that students need to learn that people program calculators to serve as tools. Therefore, calculators are not always right. They simply do what they are programmed to do. Teachers should not present calculators to be the final authority on math (Willoughby). 
The 1992 NCTM Yearbook was solely focused on the use of calculators in classrooms. At this time, the NCTM advocated for full integration of calculators into the math curriculum. However, this directive was not easy to follow. Branca, Breedlove, and King laid out some guidelines for teachers to consider when determining whether to allow calculators to be used in the classroom each day, or not (1992). Branca et al. determined that the follow five questions were key:

(1) Does the calculator allow the students to get closer to mathematical concepts being presented? (2) Will the use of the calculator in a mathematics activity increase student confidence and persistence? (3) Could the concepts be taught with an inductive approach? (4) Would the use of the calculator facilitate the study of real-life applications? (5) Will using the calculator allow assessment to be focused on relevant educational objectives?" ( p.1012).

In 1983 and 1984 the College Board allowed calculators to be used on the Advanced Placement (AP) Calculus Exam (Greenes \& Rigol, 1992). However, in 1984 they were no longer allowed, as committee members felt that it was not fair to students who did not use a calculator. Changes to the test would need to be made first (Greenes \& Rigol). The College Board made changes to the test and allowed technology from 1991 to 1994. Beginning in 1993, scientific calculators were required on the exam (Greenes \& Rigol). Morgan and Stevens (1991), through Educational Testing Services (ETS), led a study to compare the effects of using a graphing calculator on the exam verses not using one. There were three main conclusions. First, using a calculator required more time to complete the exam, but the addition of the calculator did 
not make questions more difficult on the test. Second, students with calculators did better than those without and students with graphing calculators performed better than students with scientific calculators. Finally, they found that it was very difficult to write test items that required a calculator, or that could not be solved by a student without one.

In 1997, Sandra Hinerman studied the differences between calculator usage and paper and pencil methods on AP Calculus exams. Students were given two different exams over a six week period. Each test had a portion that permitted calculator usage and a portion that did not. On the test questions of integrals, area, and volume, there was a statistically significant difference between calculator and non-calculator usage. However, on the other portions, no difference was seen. Hinerman's study cites many other studies both for and against the use of calculators. Calculators allow for "real-life" problem solving, checking answers quickly, and exploring additional topics. However, teachers continued to worry about the loss of basic skills and focus on learning mathematics instead of the technology (Hinerman).

In 1990, the College Board began to make significant changes to the Scholastic Aptitude Test (SAT) (Greenes \& Rigol, 1992). Teachers needed to make pedagogical changes to help prepare students for this test. A number of changes were made in 1994 to the SAT (Lawrence, Rigol, Van Essen, and Jackson, 2002).

Since 1942, the math portion of the SAT consisted of multiple choice questions. In 1994, the two major changes to the exam were the addition of student-produced response (SPR) questions and allowances for calculators to be used on the exam. SPR questions allowed for more reliable statistics, an elimination of student guessing, and questions that have multiple correct answers. The SAT credited these changes to the influence of the NCTM and their desire for students to solve more real-life mathematics problems and the integration of calculators into 
the classroom. The SAT put an end to unrealistic word problems on the test this year as well. Three other goals of the changes were to "(1) strengthen the relationship between the test and current mathematics curriculum, (2) move away form an exclusively multiple choice test, and (3) reduce the impact of speed on test performance" (Lawrence et al., p. 8).

M.H. Protter, a professor at the University of California, wrote to The New York Times and shared her opinions against allowing the use of calculators on the SAT (1990). She stated that calculators bring an unfair advantage to those students who are wealthy enough to own and bring an advanced calculator with them to the testing site. Even if a calculator is provided for the test, students who do not already own one or use one frequently will waste time during the test trying to figure out how to use it. Protter concluded that calculators give an unfair advantage to the wealthy and should be prohibited from the test. She also claims that students who are not accustomed to using calculators in their classrooms will waste time on the SAT trying to use them and not perform as well.

Teacher David Bernklau refuted the argument against using calculators on the SAT stating that if schools are following the NCTM's push to use calculators from elementary schools and up, then students should be fully proficient with the calculator by the time they take the SAT (Bernklau, 1990). He also pointed out that in general, it is the teacher's responsibility to create a well written exam that tests the students' mathematical knowledge and not computation on a calculator. It is also the teacher's responsibility to show students how to use calculators (Bernklau).

Scheuneman, Camara, Cascallar, Wendler, and Lawrence (2002) completed a study on the November 1996 and November 1997 SATs to determine what effect the use of a calculator had on this standardized test. All students taking these two exams were asked to complete three 
questions at the end of the SAT about their calculator use on the test. Over 200,000 students were included in the study for each year. Researchers found that $95 \%$ of the students taking the SAT brought a calculator along with them as compared to $87 \%$ of students in 1994, the first year calculators were permissible. There was also an increase of the prevalence of graphing calculators from 1996 to 1997. However, students tended to use the devices on less than half of the questions. Additionally, girls used their calculators more than boys did. Considering ethnic groups, Hispanic and African Americans brought fewer calculators to the test than Caucasian and Asian Americans. The study showed that those with a calculator performed better than students without a calculator. Also, students with a graphing calculator performed better than students with only a scientific calculator. Lastly, the study found that students, who used their calculator too often, or on too many items, took too much time and did not perform as well on the test overall. The study concluded that the calculator should be used as an aide, but not depended upon entirely to be most successful.

In Edward Ostapczuk's 1994 study of high school math teachers and principals, he found a number of conclusions about teachers' views of calculators. First, even though most school districts did not have a standard policy toward calculator usage, this did not hinder teachers from using calculators with their students and incorporating them into curriculum. Additionally, each student not having their own scientific calculator did not encumber classroom usage. Teachers also continued to use calculators though they had not been trained in this area through their districts. Pushes from state boards of education and district administrators to use calculators continually in the classroom did not appear to be practically supported through resources for teachers (Ostapczuk). 
By the late 1990s, talk of calculators and revised state standards was commonplace.

However, California seemed to be moving in a different direction. The State Board of Education voted to prohibit the use of calculators on their statewide assessment in 1997 (Lawton \& Hoff, 1997). This went along with a unanimous vote to go "Back to Basics" with their state mathematics standards for grades K-12. Opponents feared that this focus on basic skills would limit the amount of conceptual teaching and learning (Lawton, 1998).

As more standardized tests allowed and required the use of calculators, it became important to find the best calculator to fit a student's needs (Wildstrom, 1997). The options and prices of calculators varied based on the student's future plans in mathematics. At this point in time, Texas Instruments was leading the market for calculators used in education. Most schools had a specific model that they preferred their students to have (Wildstrom). But, picking out calculators for students wasn't the main problem that teachers faced. As new calculators and pieces of technology were invented, teachers were forced to not only learn how to use them but figure out how to incorporate them into their classrooms as well (Hollister Davis, 1997).

Sarah Jeanne Hollister Davis is but one example of a teacher who worked hard to incorporate new technologies and stay up to date with her students' technological learning. She attended many workshops and trainings offered by her school district and then shared what she learned in her classroom. She worked with other teams of teachers to find ways to incorporate graphing calculators into the curriculum in meaningful ways that also motivated the student. This required extra time and meetings for all involved teachers. She emphasized the extra amount of time and energy required but stated that the benefits were worth it. Additional benefits include using technology to connect math to other subjects such as history or English and analyze data that they collected in science class (Hollister Davis). 
A similar article by Marcia Tress (1998) followed a Michigan teacher through her journey of incorporating TI-83 calculators into her classroom of mathematically struggling students. Her curriculum involved solving real-life problems such as paying taxes, bills, credit cards, and balancing a checkbook. This teacher incorporated the calculator into her curriculum without detracting from it. Her observations stated that students were better able to mathematically explore on their own, solve problems, and make generalizations with the use of the calculator. Another school, in Los Angeles, noted that the graphing calculators made students feel empowered as well as motivated to continue learning, in addition to a greater ability to visualize the lesson's concept (Tress).

Yet, not all math professionals were as pleased with the widespread use of calculators. Tutor Diane Hunskaer (1997) raised many concerns after working with students continually struggling to solve basic math problems. Her students grew up using calculators in their classrooms to solve nearly every type of problem. She claimed that this has lessened their ability to think logically and clearly about mathematical processes: the goal of mathematics. Additionally, students that used calculators did not create a plan to solve the problem; rather, they tried combinations of calculator functions to find an answer. Lastly, she claimed that students who have grown up using calculators struggled with generating strategies for solving problems and actually computing answers. She claimed that calculators are prevalent in the real world, but understanding what the calculator does and why it is necessary should be taught in math class (Hunsaker).

Another concern of teachers is the question of when to incorporate calculators into curriculum (Fleener, 1995). The main question is whether teachers should wait until students have mastered a concept before allowing them to use a calculator, or allowing them to use a 
calculator before or while learning the new idea. Fleener surveyed 233 classroom teachers and 78 pre-service teachers to determine their opinions. She concluded that $55 \%$ of pre-service teachers felt that students should master a new concept before receiving help from technology. The study found that this percentage was similar to the views of current teachers. Fleener also noted that there was a correlation between experience and a mastery view of calculator usage. The more experience a teacher had, the stronger they felt on this issue. That is, teachers felt more strongly than pre-service teachers that students should master a concept before being allowed to use a calculator on the same concept (Fleener).

Elaine Simmt (1997) studied the effect of a teacher's philosophy of math on the use of technology in the classroom. She conducted a case study of six different $11^{\text {th }}$ and $12^{\text {th }}$ grade high school math teachers, observed their use of graphing calculators in a unit on the quadratic formula, and interviewed each teacher about his philosophy of mathematics and education. Her motivation for the interview was an attempt to determine why technology has not had a big impact on education, as it was predicted to do (Simmt). In her observations, all of the teachers used the graphing calculators to help teach transformations of functions and to help students generate accurate graphs. Many of the teachers also used the calculators as a way for students to check their answers. Simmt was surprised that the teachers did not all use the calculators to extend the concept instead of just teaching the basics of the topics. Some teachers also showed students the limitations of the calculators, while others allowed students to discover concepts on their own.

Upon researching the individual teachers' philosophy of teaching, she noted a common theme of all teachers: the belief that mathematics is logical and sequential. They all agreed that students should be taught one concept before building upon it to teach more in depth topics. 
They believed that the discipline of mathematics is deductive and logical. There were also many differences between the teachers. Some wanted to show students that they can learn math while others were more focused on teaching a foundational set of rules to their students. Most of the teachers in the study approved of using graphing calculators, but were cautious in changing the curriculum to use it. Most also agreed that the calculators were highly motivating for students. The research concluded that the view of mathematics and technology each teacher held greatly affected how they taught with the graphing calculator. Simply having a new tool in the classroom was not enough. Teachers needed help incorporating it into their curriculum. Simmt also noted that training teachers in using new technology would not be enough. Rather, sharing a new philosophy of mathematics and its future was necessary before changing the way technology was used (Simmt).

Milou (1998) studied the high school and junior high teachers in 52 districts through surveys of their attitudes toward the use of graphing calculators in their Algebra classrooms. His research resulted in six major findings about the attitudes of teachers. First, Algebra 2 teachers had much higher attitudes toward graphing calculator usage than Algebra 1 teachers did and utilized the technology far more often. Second, $92.4 \%$ of the teachers agreed that algebra problems are more interesting when solved with a calculator. Third, a majority of algebra teachers felt that students tried harder and were more motivated when they were allowed to use a calculator. Fourth, even though a majority of teachers used graphing calculators as a teaching tool, they admitted their lack of significant knowledge about calculator use. Fifth, algebra teachers still agreed that students should learn algebra concepts first, before introducing them to the graphing calculator. Lastly, teachers that used the calculators several times a week had more positive attitudes than teachers who used them less frequently. 
While graphing calculators are helping some kids succeed, equally concerning are the students that know more about the calculators than their teachers (Lee, 1999). As teachers change their tests to involve more problem solving and critical thinking questions, and less plug and chug questions, students tried to beat the system. High school students are learning how to create and successfully produce programs that generate answers for them. Other students are figuring out how to send answers to one another during tests. Teachers can ask students to clear the memories on their calculators before tests, but need to make sure that students are not fooling them. Ultimately, it will be the teachers' responsibility to test in a way that does not allow the calculator to answer the test for the student. Yet, teachers can be encouraged that allowing calculators on tests allows for focus on how to apply what students know, instead of asking basic questions (Lee).

In response to these concerns about calculators, Douglas Shapiro (1999) added his concern that students also did not understand the concepts behind the mathematics. He claimed that students do not fully understand what they are doing if they are only taught how to punch questions into their calculator (Shapiro). Parents also raised concerns that students could not do basic math on their own (Gelernter, 1998). Researcher Gelerneter asserted that giving children calculators to use whenever they want defeats the purpose of teaching mathematics. When students are taught, they should be gaining knowledge that they will retain, and not need to reference, or find a tool, such as a calculator, to use later in life. Without learning arithmetic, students do not have a basic understanding of math, and cannot generalize when they get older. They often will not know if they even have the correct answer because they do not have a sense what they are looking for (Gelernter). 
Under the Clinton Administration, the Department of Education began to generate a national math test to be given to eighth grade students (Lawton \& Hoff, 1997). However, the plan was halted in September upon the debate of the use of calculators. Secretary of Education, Richard Riley believed that that test should show what the students know on their own, unaided by a calculator (Lawton \& Huff). In March of 1998 an independent panel redesigned the proposed national tests and allowed for the use of calculators on approximately one-third of the math test (Lawton, 1998).

The U.S Department of Education's The Nation's Report Card: Mathematics 2000, (2001), had a number of summary results regarding calculators in schools in the United States, depending on the grade level. Unrestricted calculator use in eighth grade led to higher test scores than students with limited use (U.S. Department of Education, xvii). In fourth and eighth grades, the number of students using a calculator daily declined from 2000 to 1996. In twelfth grade, increased usage of calculators was correlated to increased scores. Additionally, more high school students reported using a graphing calculator in 2000 than in 1996 and had higher scores than students without. The NAEP's Mathematics exam allowed for the use of scientific calculators on parts of the exam. For the eight and twelfth grades student, the NAEP felt that the calculator was a technological too to help students solve problems in the portion of the test labeled Basic effectively. The NAEP continued to ask students and teachers about the prevalence of calculators in the classroom, realizing that districts and schools have varied policies about the integration of the technology. After years of collecting data, it was shown that $8^{\text {th }}$ grade students had a positive relationship between usage and higher scores. Nearly half of all $8^{\text {th }}$ grade teachers reported daily use of calculators in their classrooms. There was also a decrease in calculator usage on daily homework in $8^{\text {th }}$ graders, but not $12^{\text {th }}$ graders, from 1996 to 
2000. One of the main conclusions of the NAEP study of calculator usage was that "more frequent use of calculators was associated with higher scores at grade 12 [and 8].” (U.S. Department of Education, 162-163). Additionally, there has been an increase in both scientific and graphing calculator usage in grades 8 and 12 since 1996.

Teachers continued to find creative ways to incorporate calculators into their classes to introduce new topics and help students investigate concepts that are still too difficult to complete by hand (Jehlen, 2001). At this time, NCTM leader Stiff continued to reiterate that calculators should not be used to replace teaching arithmetic and number facts, but enhance learning and help children discover more (Jehlen).

In 2001, policies regarding calculators were still being created. Educational Testing Services (ETS) allowed students to bring in their own calculators while the NAEP required students to use a standard issue calculator (Hanson, Brown, Levine, Garcia, 2001). But, did the type of calculator affect student performance? Fifty eighth grade students from ethnically diverse schools were chosen to participate in the study. Students completed two NAEP tests and two computational tests with limited time with a standard NAEP calculator and again their own. Researchers found that using a personal or standard issued calculator did not affect the students' accuracy, timing, number of keystrokes, level of confidence in their answers, or ease of calculator usage. However, if the standard calculator was more advanced than their personal calculator, the student generally chose the standard calculator. However, if the student's calculator was equally complex to the standard calculator, they would choose their own. Other students felt uncomfortable using a new calculator. This study concluded that there is no reason to prohibit students from bringing their own calculators to tests or requiring the use of standard 
calculators. It was also found that gender, race, or family income did not affect performance with either type of calculator (Hanson et al).

The use of graphing calculators in the classroom fluctuated. In the research of Burrill et al., the 43 studies of graphing calculators and their usage reveals that teacher's views and incorporation of the technology into their classrooms varied greatly (2002). Other conclusions revealed that using graphing calculators increased higher level thinking and questioning. Additionally, the study pointed out that major changes were not typically made when calculators are introduced to the classroom. They were added as an extension of learning. Individual teacher's views of calculators and technology made a big difference on the impact of use of calculators in their classrooms. Burrill also emphasized the importance of showing students how to use the calculator and think through how to use it on their own. This will minimize calculator misuse. Students needed to be shown the potential and limitations of their calculators to understand when it is appropriate to use it or not. There were also a number of specific skills gained by students through the use of graphing calculators: increased used of graphing to solve problems, more frequent student exploration of mathematical concepts, and using additional tools and methods to solve a problem (Burrill).

After studying the history of calculators in mathematics, Waits and Demana (2000) determined that balance is key. They recommended a balance of calculator usage as well as paper and pencil work. Students need to understand the concept at hand, but should be permitted to use their calculators to help with the computation part of problem solving. Students also need to be shown how their calculators support and confirm the mathematics that they do by hand, in addition to helping them determine when to use a calculator (Waits \& Demana). 
Eric Milou (1999) surveyed 146 junior high and high school math teachers regarding their use of graphing calculators. His results were mixed, showing that there is still controversy over their use. He found that graphing calculators are embraced by Algebra 2 teachers for a variety of topics. However, middle school teachers and Algebra 1 teachers have not full accepted their usage. These teachers said that there was little pressure for them to incorporate the technology into their curriculum. They were also unsure how to go about using the calculators in their lessons. This could be in part to a lack of curriculum changes designed to add the calculator into daily learning (Milou).

Quantifiable results from the use of calculators still remain under great study and debate. A meta-analysis of 54 studies was conducted in 2003 to find conclusive results for the effects on calculators on students' mathematical abilities as well as their attitudes (Ellington). The report showed a number of findings. Briefly, the study showed that when calculators were allowed in during times of instruction, but not during assessment, students maintained paper-and-pencil skills and their ability to conceptually understand mathematics. Studies also showed the necessity of calculator usage and instruction for at least a period of nine weeks to see the greatest benefit (Ellington).

The next group of findings included studies of calculator usage both in the classroom and on assessments. These students showed a gain in operational skills, paper-and-pencil skills, and mathematical concept skills. Here, students benefited most from a short use of calculators, less than three weeks, or a more consistent teaching period of more than nine weeks (Ellington). The type of calculator did not matter when assessing operational skills of students. Lastly, student attitudes were found to be effected by the use of calculators. Attitudes of students had the 
greatest improvement when calculators were used for at least nine weeks. Graphing calculators also influenced student attitudes more than other less complex calculators (Ellington).

Sweeney (2004) generated a qualitative study of the attitudes of parents in regards to calculators being used in middle school. Sweeney conducted initial surveys and interviews of parents to find a baseline for their attitudes, which were generally neutral. Then, after sending home a discovery lesson and newsletter to parents, she conducted more interviews and additional surveys. In general, most of the parents showed much more favorable attitudes at the end of the activity attributed to their realization that calculators could be used for learning and discovering as opposed to simply computations. Many parents attributed their change in attitude to the discovery learning lesson, but others did not like this new approach fearing that it would take away valuable instruction time. Parents still had concerns at the ends of the interviews, but overall were more favorable to calculators being used in middle and high schools. Some of their remaining concerns included a fear that students wouldn't learn basics, the benefits of doing math by hand would be lost, and the students' estimation skills were still lacking for the calculator to be effective. Others still feared that the calculator would begin to take the place of the teacher and kids would become dependent on it (Sweeney).

In 2005 , the NCTM set out to clarify their position on calculators in the classroom by answering the question, "Is there a place for both computation and calculators in the math classroom?" (NCTM, 2005, p.1). The NCTM put responsibility on teachers to help students learn when it is appropriate to use technology to help solve problems, when pencil and paper should be used, and when mental math is the best method. Teachers also need to use calculators to expand student knowledge and increase their number sense. Increasing number sense through estimation, mental math, and a good understanding of addition, subtraction, multiplication, and 
division will help students to solve more problems in the real world. A main goal is for students to be proficient in number sense, specifically involving situations of size, distance, and magnitude. They reassured the public that students do need to be proficient at basic math skills. However, they did clarify that using pencil and paper to solve long problems was not necessary with the availability of technology now.

The policy change by the NCTM in 2005 had administrators and teachers moving their curriculum back to teaching the basics (Hechinger, 2006). The plan was to focus more on student acquisition of skills and fundamental concepts. No longer should teachers focus on estimation skills and approximate answers that help students determine if their calculator gives them the correct answer or not. This form of teaching will resemble the methodology and curriculum of many Asian countries. These countries focus on a few concepts and learn them very well. Complaints have been raised that students do not understand what is going on with the math that they do on their calculator. Simply, that they got an answer (Hechinger).

Laumarkis and Herman (2006) conducted a study on the connection between teacher training and student performance on state tests in Florida. High school math classrooms in Florida used TI-83 Plus calculators, but the devices were not permitted to be used on state assessments. Ten teachers were given specific instructions on teaching with the TI-83 Plus calculator in their classrooms and seven teachers were not. Those who were trained attended workshops sponsored by Texas Instruments on teaching for a test called Algebra Assessments. Training was divided into nine parts that included pedagogical ideas, specific skills, linear functions, graphical representations, polygons, and transformations. 569 students were involved in the study: 360 were taught by teachers trained for this study and 209 students were taught by teachers without this specific training. The study found that students who were taught by these 
trained teachers made greater increases on the Florida Comprehensive Assessment Test, even though they were not permitted to use a calculator. Researchers concluded that the training workshops that 10 of the teachers attended were an effective way to help raise test scores for students (Laumarkis \& Herman).

A meta-analysis of 42 studies of student's access to graphing calculators revealed mixed results (Ellington, 2006). When students were taught daily instruction with a calculator and were able to use a calculator on assessments, students had higher scores $60 \%$ more often than students without the technology. However, students that used calculators in class, but not on tests, did not show any greater knowledge or achievement. But, they still had a greater mathematical understanding. The analysis also revealed that students using calculators had a $58 \%$ better attitude toward mathematics (Ellington). The attitudes of teachers were not analyzed, but the studies gave support for teachers to continue teaching and assessing students with this technology.

An extensive study of K-12 teachers and the connection between their personal beliefs about calculator usage and their classroom instruction in 2007 revealed interesting connections between the two (Brown et al.). Questionnaires and self-reports were gathered from 816 teachers working at 26 high schools, 29 middle schools, and 86 elementary schools about their beliefs, knowledge, and practices of calculator usage. The average years of experience of a teacher were greater than 14 years. Significant connections were found. (1) Teachers of all ages agreed that their students learned math by using a calculators and are more interested in the topics. (2) All teachers agreed that students improved with the calculators but the teachers also wanted students to be able to show work by hand. (3) It was also agreed upon that using calculator does not lower a student's achievement or their scores on standardized tests. (4) Teachers also used 
calculators with all of their students, not only struggling students. (5) Classroom inequities did not seem to appear while some students had calculators to use at home and others did not.

High school teachers also felt that calculators were not to be used as a replacement for learning mathematical facts and procedures. Middle school teachers had the highest belief that calculators should have limited use: to check computation, when a concept has already been learned, or for students with special needs (Brown et al.). It also appeared the elementary teachers had the most difficulty balancing calculator usage in their classrooms. All teachers also felt that calculators encouraged higher-level thinking and encouraged greater understanding and higher student performance. They also noted that teachers used the calculators for student investigations of math concepts and for increased positive attitudes (Brown et al.).

A study by Chamblee, Slough, and Wunsch (2008) enrolled 22 high school math and science teachers in a professional development program for one year that focused on training teachers to incorporate graphing calculators into their curriculum. Collecting, representing, and analyzing data were the main skills focused upon. Researchers assessed the concerns of the teachers at the beginning and end of the school year. The study reports that the teachers' knowledge of the graphing calculators, exploration of the technology, and implementation had all increased at the end of the training year. Additionally, the math teachers spent extra time learning how to apply new applications and reflecting on the benefits of implementing the calculators in their classroom. The teachers were still concerned about fully using graphing calculators in their classrooms, as they were at the onset of the study. Also, as teachers received increased training, they became more concern about how to best incorporate the new technology into their classroom. Teachers continued to desire information of how to teach specific skills in 
their classroom with the calculators. These desires can be met by further training, workshops, or in-services (Chamberlee et al.).

Findings from a Vanderbilt University study show that students with a basic knowledge of their math facts benefited more from the use of a calculator than those without the knowledge (“Calculators OK in Math," 2008). For students who already had a basic knowledge of multiplication, using a calculator did have an impact on them. But, for students who did not have good multiplication skills, the calculator harmed their performance. Confirming the results of other studies, students benefited from the calculators by being able to check their answers and practicing more. When evaluating younger children, the study concluded that it is important for students to first learn how to compute. Only then teachers should readily embrace using technology ("Calculators OK in Math").

Schools continued to expand their use of technology by adding TI-Navigators to their math classrooms (Cavanagh, 2006). This system of graphing calculators includes a feature that transmits answers and data from every student's calculator to the teacher's computer. Teachers used it for up to date progress of students as well as giving quick quizzes. Teachers also posted a question through the projector screen and have students answer immediately on their calculators. This allowed teachers to change lesson plans mid class when they receive feedback through students. They were easily able to determine how many and which students are grasping the lesson's concept through a formative assessment on the calculator. This also allowed teachers to know how each student is doing and how well they understand, instead of just hearing from students who typically raise their hands. Costing nearly $\$ 10,000$ per classroom, many teachers say the investment is worth the money as it enhances student learning. An Ohio 
school district saw math scores that doubled on state standards tests after using this technology throughout the year (Cavanagh).

The history of calculator usage in junior high and high schools is characterized by certain ebb and flow. State school boards, the NAEP, the NCTM, and the College Board among other institutions have lead changes over time through their support or rejection of calculators. Movement forward was often met with resistance and a backlash was evident. The attitudes toward calculators are fluid and ever changing. Parents, teachers, and administrators are often left in limbo to react to changes in policy. When calculators first became available to the general public, their use was rampant. Educators were forced to determine policies to control or emphasize their use. Parents feared the changes in education and the effects the minicalculator would bring to the quality of education given. As the years wore on, research increased, giving support to legislation and opinions about the new technology. Standardized tests such as state tests, AP exams, and the SAT began to reevaluate and adapt to utilize this new technology. Yet, throughout all of these changes, reactions were varied. Support for calculators increased, decreased, and was challenged. How do all of these changes and attitudes fit together? Can sense be made of this history? 


\section{Methodology}

The world around us is constantly changing, and the realm of education is no exception. New technology, pedagogy, curriculum, and research are continually challenging the way we teach and direct our education system. But, what causes these changes? Can they be explained, or can we see them coming? Though change cannot be prohibited, those involved can be better prepared to handle the modifications necessary to adapt if they understand. Historical analyses can be used to provide insight to educators, parents, and students alike as we seek to educate our children in and for the future.

The purposes of research are many, including, "exploring, describing, predicting, explaining, or evaluating" (Guthrie, 2003, p. 2021). Practitioners, policymakers, and researchers are the three audiences of research (Conrad \& Serlin, 2006). They utilize presented research according to their various needs. In the case of education, some are looking for answers to problems in their classrooms; others use it to make decisions, while yet others still make connections to past research or to a need for further investigation in the future (Conrad \& Serlin).

Historical analyses are but one form of research. "A history is an account of some event or combination of events. Historical analysis is a method of discovering what has happened using records and accounts." (Marshall \& Rossman, 2006, p. 119). In addition, looking at history can shed new light on our culture and its ever changing nature. It can help determine if technology has changed society for the better or worse in addition to helping consumers better understand the context of the change (Wyche, Sengers, \& Grinter, 2006). Historical analysis involves a methodical approach to analyzing primary 
and secondary sources in their original context and together as a whole (Peterson, 2006).

Examining primary sources helps deepen understanding. Peterson explains that

researching and understanding history involves "gathering evidence, analyzing and interpreting evidence, developing an understanding of context, and drafting narratives and arguments." (p. 294). A historical analysis includes the previous steps as well diving deep into available artifacts. To synthesize a historical analysis, researchers need to know the purpose of the artifacts, the reason for the creation of the documents, how all of the sources are connected, and if they are in agreement (Peterson).

The study of history is synonymous with the study of what has happened in the past from records and accounts (Berg, 2001). Its goal is "to fashion a descriptive written account of the past. Such a narrative account is flowing, revealing, vibrant, and alive!" (Berg, p. 210). It is bringing together people, events, meaning, and ideas from the past in order to understand how they have influenced the present day. It is the study of relationships and human behavior. It finds implications, connections, and adds to the understanding of human culture (Berg).

\section{Rational for Method}

Since calculators were first invented and widely available, they have been used. They are commonplace in homes, school, business, and other environments. The popularity among $21^{\text {st }}$ century students and adults alike ensure their prominence. The creation of better, faster, and more modern calculators show they will not become extinct from society in the near future, if ever. Their replacement is not foretold yet, either. The question is not, "will calculators continue to be used?," but rather the debate lays in how they will and should be used. This thesis seeks to answer two dilemmas: "What major 
historical events have changed how calculators are used in the classroom?" and "how have the reactions of teachers, parents, and administrators effected calculator usage?"

When considering the research questions, quantitative research clearly will not work. The study of historical events, people's reactions, created polices, and advances in technology cannot be adequately measured by statistical means. Qualitative research is more ideal for the theoretical nature of this topic. Qualitative research is concerned with the social world, it is "flexible and sensitive to the social context" (p. 3) around the research, and is a more holistic way of analyzing research (Mason, 2002). To study the change of attitudes and historical events of the past lends itself to answer the question of this thesis. In addition,

"Historical analysis is particularly useful in obtaining knowledge of unexamined areas and in reexamining questions for which answers are not definite as desired. It allows for systematic and direct classification of data ... Many research studies have a historical base or context, so systematic historical analysis enhances the trustworthiness and credibility of a study" (Marsha \& Rossman, p. 119).

If the purpose of research is for a researcher to be "exploring, describing, predicting, explaining, or evaluating" (Guthrie, 2003, p. 2021), a fresh viewpoint should be brought. The research on calculators in the last four decades is seemingly endless. Online databases easily return over 12,000 documents on calculators in vast array. It is a continual topic of interest for teachers as well as organizations such as the NCTM. Historical studies by the Conference Board of the Mathematical Sciences (1975), Suydam (1982), and Waits \& Demana (2000) 
have been completed on the history of mathematics education and include the influence of calculators. In addition, studies such as Ellington's (2003), Laursen's (1978), Milou's (1998), and Vaugh's (1976) have focused on the effects of calculators on students attitudes. There have also been studies on the attitudes of parents, such as Sweeney's in 2004. However, these studies have yet to be examined in one document. In addition, there has not been a study that observes the attitudes of parents, teachers, and administrators in regards to calculator usage and their opinions of it over time.

This thesis gives a new perspective on attitudes toward calculator usage. The study includes the history of calculator usage in general as well as attitudes of different groups of adults toward the topic. The researcher identified the key eras of time in the history of the calculator that have brought us to this current time period. The report reviews the development of new technology since 1975 and the effects it has made on our educational system. It also explores policy changes by the NCTM, The College Board, and other prominent educational organizations and the effects their rulings have created. This form of research has yet to be synthesized.

\section{Procedure}

This study assesses the impact of the historical contributions of the calculator and people's reactions toward them as they became a standard part of math education. A focused look back on the impact of this technology since 1975 will help us understand our current state in mathematics education as well as give insight to its' future. 
"In historical analysis, researchers consider various sources of historical data such as historical texts, newspaper reports, diaries, and maps. The method is commonly used by historians to gain insights into social phenomena." (Wyche, Sengers, \& Grinter, 2006). By gathering a variety of documents from available sources, research tells us the key historical events in the history of calculators.

Extensive research of online databases provided the majority of the secondary works cited in this thesis. The search of applicable research began with education related databases including Education Research Information Center (ERIC), PsycINFO, SIRS Researcher, Education Research Complete, Professional Development Collection [Educators], and Education Full Text. More specialized databases such as Scopus, MathSciNet, and Science Citation index Expanded (ISI) were used. Keys words such as calculator, high school, middle school, parent, teacher, and attitude were used, often in different combinations to yield maximum search results. Dissertations Abstracts was searched with keywords calculators and students. GoogleScholar was also searched using key words such as high school student, teacher, calculator, and math.

In addition to published research, popular and social media sources were also helpful. MasterFILE Premier was used with key words such as calculator, high school, middle school, parent, teacher, and attitude. MasterFILE was searched by decade for additional research. Searching The New York Times website database for any articles with the keyword calculator also offered many resources. Reading articles from popular news sources such as The New York Times or Newsweek provided deep insight into the attitudes of the time period at hand. These articles allowed for feedback, such as letters to the editors, as well as public criticism or approval. 
The Cedarville University Library Collection also provided a number of books that were helpful for research. The collection was searched with the keyword calculator. A perusal through the Mathematics section of the library revealed further sources. NCTM yearbooks and other publications were particularly helpful from library. These sources compiled articles of research from the current year to describe trends in mathematics.

Additionally, the archives of the National Council of Teachers of Mathematics provided awareness of the changes in policy over time from this leading mathematics education organization. Using an NCTM website account to access archives not available to the general public provided past statements and positions on technology.

"A Historical Perspective on the SAT 1926-2001 (2002) was also beneficial for understanding changes made by The College Board and Educational Testing Services in regard to changes in standardized testing. The combination of all of these sources expanded the researcher's knowledge of calculators and their effects. Once sources were read, bibliographies of articles were inspected for additional resources that may be helpful, but had not turned up in previous searches. The researcher thoroughly explored available resources for those both for and against calculator usage in the American public school system.

Once all resources were found and collected, they were read and analyzed to see if they met certain criteria to be useful and applicable to this historical analysis. The earliest research, prior to 1980 was considered and chosen with a looser set of standards than later research. Nearly any research from 1975 to 1980 about calculators, student usage, or attitudes was included in this study. The articles may not have related directly 
to attitudes of teachers or parents in regards to calculator usage, but research was in its very basic stages in regards to calculators. Since this was the time when calculators were first brought into mainstream life, any articles or research was helpful for generating a baseline for the study.

As calculators became more popular, research also grew. Therefore, criterions were selected to determine if articles would be helpful for this analysis or not. At the most basic level, an article had to meet two basic standards. First, an article needed to involve students or parents and teachers of children in at least the seventh grade, but before high school graduation. Studies of students in elementary grades or at the collegiate level were not included. Additionally, studies and articles needed to be based on mainstream, public high school classrooms. Studies involving private schools or special education classrooms were disregarded.

Research for this analysis came from two main sources: academic research and popular news sources. Each of these types of articles was reviewed differently. Popular news sources such as The New York Times, The Wall Street Journal or Newsweek articles were included in this study if the subject of the writing was calculators and their impact on students or education. The inclusion for these articles in this study was broad, as many of the articles were editorials, news summaries, or opinion columns on education and mathematics. Newspaper or magazine articles that cited changes in education due to calculator usage were also included, as they helped define historical changes and give structure to this study. If comments or editorial comments to these articles were found, they were also included. 
Academic articles and research followed a stricter criterion in order to be included. These articles needed to fit in one of these categories: (1) a history or survey of calculators or their use, (2) parental opinions or attitudes, either through a researcher's survey or their own editorial accounts, (3) teacher opinions and attitudes toward calculators in their own classrooms, typically after implementing new technology or through their own training experience, (4) a major work or statement from a well known education organization such as NCTM or NAEP, or (5) issues related to standardized tests.

Once the popular new source and academic research articles were collected, they were read and organized both chronologically and categorically. The chronological organization aided the literature review and helped to create a big picture of the past four decades of calculator usage. The overall ebb and flow of change of historical events as well as attitudes and reactions could be seen on a large scale. This also led the researcher to generate the five key time periods of calculator use and change to be described later. The categorical organization of the articles allowed the researcher to identify key themes and changes within the specific categories. The study was now able to analyze changes within parent and educator attitudes, as well as policy changes by the NCTM and other national educational organizations.

After analyzing the available research of the use of and attitudes towards calculators, the researcher divided this time period into five major eras from 1975 to the present day. They are: "The Great Divide," "An Era of Action," "The Graphing Calculator Epoch," "A Strategic Decision," and "A Period of Confusion.” These divisions were carefully studied and chosen. Common themes, research, and reactions 
were considered to make these partitions. The periods do have years of overlap, as common themes occurred at the same time. Major decisions and declarations by prominent education groups were the cause of some of these creations. However, others occurred due to the reactions of teachers, parents, and researchers. In addition, the creation of new technology by Texas Instruments and other companies were influential. Each period was affected by new research, assertions from educational organizations, and the attitudes of parents, teachers, and other educators. Significant studies, scholars, reactions were noted in addition to the effects that they created. The researcher also included a summary and analysis of each era and the effects it has on students, teachers, and the future of mathematics education.

After the identification of the key events and reactions for each of these eras, this study includes the implications of these findings. The discussion of these events is crucial. The consequences of these eras continue to affect education today.

\section{Conclusion}

"Historical analyses of social knowledge, traditions, and conditions can increase appreciation and understanding of contemporary issues of health, race relations, crime and corrections, education, business trends, and an infinite array of social, political, and spiritual realms" (Berg, p. 211). This historical analysis is meant not only to study the past and the common themes linking the past to the present. But, to understand how the past has affected the current state of education and the implications it has for the future. Though the future cannot be projected, the past will certainly lend a predictive key. 


\section{Results \& Analysis}

Since 1975 the use of calculators in school has greatly increased while policies, curriculums, and attitudes have changed towards it. Yet, the changes have not all been with forward momentum. Movement forward has been met with resistance, yet the technology has prevailed. These changes have been driven by four major groups: the NCTM, parents, educational organizations, and teachers. The attitudes and roles of these groups have been analyzed from 1975 to the present day in order to understand their influence. Before diving into these four groups and observing their changes over time, a summary of the eras of calculator use is presented.

Research from the past 4 decades has been analyzed for common themes and events in order to understand the period of time. These periods will be a helpful reference when examining specific groups of interest and the impact that their attitudes and decisions have had on mathematics education through the use of the calculator. The periods of time are: "The Great Divide," "An Era of Action," "The Graphing Calculator Epoch," “A Strategic Decision," and "A Period of Confusion.” As previously mentioned, some of the periods of times have years that overlap, as change is not always linear. Also, themes were occurring at the same time, making it impossible to partition the periods of time uniformly.

The Great Divide The Great Divide is the era from 1975 to 1979 . It is summarized by a debate of confident organizations verses skeptical laymen. During this time, organized education associations, such as NACOME, encouraged and mandated the 
use of calculators, but due to the lack of published research and study, parents and teachers remained unsure. NACOME recommended that all students in eighth grade and high school have constant access to calculators in the classroom (Conference Board of Mathematical Sciences, 1975). Yet, $72 \%$ of teachers, mathematicians, and laymen did not want calculators to be used in high school (Pendelton, 1975). Rudnick and Krulik (1976) completed one of the largest research studies on the topic at this time and found that parents had strong reservations for allowing calculators into the classroom for fear that their children would forget their basic math skills.

In 1978, in an official statement, the NCTM shared their request that calculator usage increase in the classroom, as they felt it would grow more favorable student attitudes and help them solve more real life problems (Taylor \& McKean, 1979). The NAEP also directed schools to use calculators more often in order to improve student computational competency (Suydam, 1982). By 1979, only 3\% of teachers surveyed by Wyatt, Rybold, Reys, and Bestgen, had calculators available to them for their classrooms. They had also not been trained on how to use them. Teachers continued to fear that students would not be able to do basic computation if they were given a calculator. This conflict in the first beginning era of calculator usage set the tone for many years to come. It showcased a need for research in order to draw conclusive and well supported opinions for both teachers and national organizations.

An Era of Action The period from 1980 to 1992, here defined as An Era of Action was characterized by the beginning of intensive research leading to educators and legislators taking action. At the beginning of this time period, nearly every student had access to a calculator (Seitz \& Parks, 1982). This prodded the NCTM's Agenda for 
Action (1980) to emphasize the importance of calculators for discovery learning. But, how were they to be used? The majority of schools did not have policies for calculator usage (Roberts, 1980). Still, $47 \%$ of students were not allowed to use calculators on assessments. At this time, research showed that calculators were helping students increase their computational skills (Roberts). Bitter found that teaching workshops on instruction and activities with the calculator was necessary to generate more positive attitudes in teachers about incorporating the new technology in their classroom (1980). Research led a few states to begin mandating calculators on their standardized tests. In 1986, Connecticut was the first state to begin this new procedure (Libov, 1986). Also, by 1991, calculators were permitted and then mandated by 1992 on the New York Regents exam. The city of Chicago and later the state of New Jersey began to distribute calculators for free to each student in their school system ("Chicago Provides Free Calculators to Students," 1988). Research on students taking the Iowa Tests of Educational Development showed that students with calculators performed slightly better than students without the device (Ansley, Spratt, \& Robert, 1989).

One of the biggest events during this time period was the statement from the NCTM that students should have calculators all of the time (NCTM, 1989). Teachers and administrators were left to alter curriculum and training to follow suit and parents were unsure of what to believe. Some parents hesitated to jump on board, fearing the long term results of a lack of mathematical ability would disservice their children (SandbergDiment, 1986). A study of parental attitudes after a two year study on their middle school children and calculators revealed that $40 \%$ of parents were still concerned for their child's computational skills if permitted to use calculators (Bitter \& Hatfield, 1993). A 
publication by The National Research Council in 1989 compiled evidence and synthesized a number of reasons in support of calculators. Calculators were a tool for motivation and exploration of realistic data. Intensive studies by researchers of all kinds on parents, teachers, and students using calculators began to provide great insight into the future of the calculator as an educational tool. Without this research opinions would have been unfounded and plans for the future could not be made and trusted.

The Graphing Calculator Epoch The era of the graphing calculator occurred from 1991 to 1999 beginning when it was first available for widespread use. This advanced piece of technology lead to major educational changes. Throughout the course of the 1990s, graphing calculators evolved from newly affordable and available to rampant in classrooms (Gunstein \& Lipsey, 2001). Teachers could use this new technology to convert rectangular to polar graphs, use dual graphing screens, store and print data, among other tasks (Gunstein \& Lipsey).

Teachers would also now need to focus on the topics of domain and range in order for students to fully understand graphing and functions (Barrett \& Goebel, 1990). Students appeared more motivated using the graphing calculators, potentially due to more cooperative work, easier visualization, and the novelty of the technology (Ryan, 1992). Others felt empowered and more able to solve real life situations (Tress, 1998). Milou (1998) studied a number of Algebra 1 and 2 teachers and their use of graphing calculators as a teaching aid. He found that Algebra 2 teachers utilized the technology often and that their students tried harder to understand when they were permitted to use the technology. A majority of teachers acknowledged that they still needed training on how to best teach with the calculator. Burrill et al. published a study on graphing calculators showing that 
the technology increased students' levels of thinking and questioning in math classrooms. He emphasized the importance of teaching students how to use the calculators, when to use them, and the limitations of the technology. In 1999, Milou continued to find controversy over the use of graphing calculators. They were still not being fully utilized by teachers teaching math at levels below Algebra 2 .

By 2000, graphing calculators were well accepted in math classrooms and research was still being completed. Laumarkis and Herman (2006) studied the effects of teacher training on student test scores. The training helped both students and teachers become more proficient and set a standard and reasoning for the necessity of this training. Students had a greater concept of mathematical understanding, but not necessarily a greater knowledge (Ellington, 2006).

A Strategic Decision The period of A Strategic Decision is the time in history where college entrance exams begin to set the standard for calculators and math education between 1993 and 1998. Changes by the College Board to the Advanced Placement (AP) Calculus Exam began slowly in 1983, but it was not until 1993 that calculators were first mandated on the exam (Greense \& Rigol, 1992). Research during the trial years indicated that students using a calculator scored higher than students without. But, major changes to test questions were not seen as an effect of using the device (Morgan \& Stevens, 1991).

In 1994, students began to see changes to the math portion of the SAT (Lawrence, Rigo, Van Essen, and Jackson, 2002). The addition of the calculator being used on the exam and student-produced response question were credited to mandates by the NCTM that technology should be a greater part of math education. However, not everyone was 
excited about the changes to this well known test. Many argued that students with less financial resources were left at a disadvantage (Protter, 1990). Research on the 1996 and 1997 SATs showed that students with calculators performed better than those without. But, students used a calculator on less than half of the SAT questions.

A Period of Confusion A Period of Confusion is defined by mixed research results that lead to further training of teachers and fluctuation from 1997 to the present day. The U.S. Department of Education's The Nation's Report Card: Mathematics 2000 (2001), was a published summary of mathematics education in America and how calculators were contributing to it. There was a positive correlation for $8^{\text {th }}$ grade students between using calculators and earning higher test scores. Yet, students were using calculators on their homework less in 2000 than in 1996. Studies also showed that there was no difference in test scores for students who had their own calculator or used one provided by the school or organization (Hanson, Brown, Levine, Garcia, 2001).

In her meta-analysis of 54 studies, Ellington (2003) was able to glean many conclusions. Students were able to maintain their paper-and-pencil skills on assessments that calculators were not permitted on, even if their classroom instruction included the technology. Interestingly, in order to maximize the benefits of calculator usage, students needed to us a calculator consistently with instruction for at least nine weeks. But, gains in operational skills can be seen after only three weeks. In 2006, Ellington also found that students who used calculators in class, but not on tests, did not show greater achievement than students without any calculator use. Yet, their attitudes were much higher. 
Other educators complained that students were becoming overly dependent on calculators and were unable to think on their own (Hunskaer, 1997). She claimed that the calculator was inhibiting students' ability to think logically and clearly about the subject. She also stated that students had a greater difficulty problem solving. Parents raised concerns over their children's future as well (Gelernter, 1998). There should be an emphasis on students knowing mathematics through retainable knowledge not simply knowing how to find a calculator to solve their problem (Gelernter).

One of the main concerns repeated by educators, parents and researchers alike is the dilemma of when the appropriate time to introduce a calculator to a student occurs (Fleener, 1995). Fleener found that over half of pre-service and current teachers wanted students to understand a new concept before using technology. But, this was not always followed in practice. Simmt also researched teacher philosophies and the effects on using technology in their classrooms (1997). Her findings indicate a high level of influence between philosophy and use of technology. This leads researchers to notice a need for a change in our teacher education and philosophy of technology in order to impact the future (Simmt). A 2007 study on teachers and their beliefs about calculator usage found that teachers were in agreement on the importance of using calculators and the necessity of students to show work by hand to learn better. Teacher training also increased teacher knowledge and willingness to implement calculators into their classrooms, even though they still had reservations about using it (Chamblee, Slough, \& Wunsch, 2008).

The summaries of these five major eras in the history of calculators will serve as a foundation for further conclusions. These eras will help to complete an understanding of 
the changes in attitudes of educators, parents, and educational associations over time. They will be referenced as the historical foundation for change.

\section{Major Groups Considered}

This historical analysis focuses on the changes of attitudes of parents, educators, and educational organizations regarding calculator usage since 1975 when calculators were first available and readily used by the general public. The remainder of the analysis is done categorically, focusing on the groups of people involved and how they have changed over time. The groups focused on are: the NCTM, parents, national educational organizations such The College Board, Educational Testing Services, and the NAEP, and educators.

The NCTM As one of the leading mathematics education organizations in the United States, the National Council of Teachers of Mathematics (NCTM) set the precedent for calculator usage. In 1978, the NCTM released their first statement on the topic with a promotion for increased usage in the classroom in order to help students solve more realistic problems (Taylor \& McKean, 1979). Though they did not want calculators to replace a student's learning of computation, the NCTM believed that calculators would motivate students to learn more (Taylor \& McKean).

Just two years later, in 1980, the NCTM's Agenda for Action was published with much stronger insistence for educators to teach with calculators. Calculators were to be fully integrated into instruction through exploration and discovery by students. The most startling point included that all students have access to calculators for their entire education in mathematics. The NCTM also advocated for teachers to interact with parents more, sharing the importance of calculator usage. The NCTM noted specifically 
that when students are doing computations, if the numbers become too large, and value is not added by doing the computation by hand, calculators should be used. The NCTM had the student's futures in mind as they made these sanctions. They believed that in order for students to be successful in the future, they would need to be technologically prepared and calculators would help meet this goal ("Mathematics teacher urge course reform," 1980).

Later that same decade the NCTM's Principles and Standards for School Mathematics (1989) summarized the changes that American mathematics education programs were going through and recommended changes for the future. The ultimate goal of these changes was to produce high school graduates that could use mathematics skills to successfully compete in real life ("Math Standards," Education Digest, 1989). There was repetition of the belief that students should have access to calculators all of the time (NCTM, 1989). However, the NCTM wanted all students to have access to calculators with graphing capabilities in the near future. The NCTM content standards for school curriculum now included sanctions on how to include technology into the curriculum. They wanted to produce exciting math classrooms where students were free to make conjectures, discover on their own, and be highly motivated to learn. Specific examples of how to teach with calculators and research continued to be done following these reports. The 1992 NCTM Yearbook focused on calculators in the classroom with the intention of helping teachers understand how to fully integrate the technology into their curriculum. Researchers helped teachers by trying to summarize main questions for teachers to ask themselves when trying to discern whether to use calculators or not (Branca, Breedlove, \& King, 1992). 
Yet, fully integrating calculators was not fully supported by teachers and parents. In 2001, NCTM leader Stiff reiterated that calculators were to be used to enhance learning and help students discover more on their own. He stated that calculators were not to replace the teaching of arithmetic. However, more clarification on the NCTM's policy was needed. In 2005, an official statement was published to clarify the NCTM's view of calculators. The confusion revolved around the answer to this question: "Is there a place for both computation and calculators in the math classroom?" (NCTM, 2005, p.1). A resounding "yes" was heard. Yet, the responsibility was clearly placed on teachers to develop philosophies and practices of technology usage. The NCTM wanted teachers to ensure appropriate use of technology. Teachers were instructed to help students choose between the methods of mental math, calculators, computer, or pencil and paper in different situations. One of the main goals of the NCTM was for students to be proficient in number sense and basic skills. Thus, teachers were responsible for making sure that these goals were met as well.

The NCTM's position on calculator usage has remained fairly consistent since 1978 when calculators were first widely available. However, as time wore on, the organization seemed to pull back the reigns a little bit and tighten their position. Instead of a blanket push for students to use calculators all of the time, as they said in 1978, they clarified that students need to be taught appropriate usage of the calculator with a basic knowledge of knowing when to use it and when to not.

Parents Throughout the past four decades, parents have been an active presence and voice in the ups and downs of using calculators in their children's classrooms. Overall, parents have been excited about the opportunities for their children that the 
calculator would provide, yet concerned at the cost at which they would come. In 1976, Rudnick and Krulik published some of the earliest research on parental attitudes regarding their student's calculator usage in schools. The year long study began and ended with an attitude assessment of the parents. At the onset, parents feared that their children would become less competent at paper and pencil tasks and forget what they had learned as a result of using a calculator. After a year of calculator usage in their children's classrooms, these same parents were surveyed again. Parents continued to have reservations about incorporating the new technology. They continued to fear that their children would become dependent on the technology and forget their basic mathematical skills. However, not all of the reactions disapproved of the technology. Many parents wanted their students to be taught how to use the calculator in addition to appreciating the attitude improvement that it brought. Ultimately, parents wanted their children to learn how to and use a calculator once they had mastered basic skills (Rudnick \& Krulik).

As time wore on, parents continued to voice their concerns about the technology in their children's classrooms. One father, Erik Sandberg-Diment (1986) shared his fear that without learning math mentally or by hand, students would not have a "feel" for math. They would not understand what type of answer they were looking for and ultimately would not know if the calculator gave the correct answer. He claimed that students needed practice mentally solving problems to maintain conceptual skills (Sandberg-Diment). In 1992, parents were still viewed as a main obstacle to incorporating calculators into the classroom (Bright, Lamphere, \& Usnick, 1992). This study claimed that parents were not on board with the claim that calculators enhance 
education and help children solve problems. The purpose of the calculator was not solving simple computations (Bright, Lamphere, \& Usnick).

Research on specific calculators in classrooms was also used to determine the most effective technology for teachers to use. The Texas Instruments Math Explorer Calculator was designed for middles school students and was tested on seventh- and eighth- grade students by Bitter and Hatfield (1993). Students used the calculator both at home and in the classroom for a school year hoping to increase student thinking, problem solving, and critical thinking. At the end of the study, overall, parents had a positive view of their children using this calculator. Also, $90 \%$ of parents wanted this new technology to be a standard part of the curriculum, while $12 \%$ of parents disagreed that it was useful for solving fractions. Still, $40 \%$ of parents felt that the calculator hindered their child's computational skills (Bitter \& Hatfield).

This view that children were having difficulty doing computation on their own continued prominently (Gelernter, 1998). On a more philosophical level, Gelernter claimed that allowing students to use calculators was contradicting the underlying foundation of mathematics education. If the purpose of mathematics is for students to gain and retain both factual and procedural knowledge, a calculator did not align with this view. A calculator was a tool for students to use to solve problems. The knowledge from math class was now no longer retained, simply referenced when they used a calculator to do the work for them. Students were lacking in arithmetic skills and a basic conceptual understanding of mathematics resulting in an inability to generalize mathematics as they grew older. Parents were also concerned that their children were also not able to identify 
if a calculator was correct or not because they did not have a deep enough understanding (Gelernter).

Most recently, Sweeney (2004), surveyed parents of middle school children to find a baseline of their attitudes toward calculator use. He found that parents were generally neutral on the topic. Then, Sweeny sent home a newsletter to parents and instructions for a discovery lesson to do at home. After the lesson was concluded, Sweeny surveyed the parents again to observe their change in attitude, if any. Many parents stated that their attitudes toward the calculator were more favorable after completing the discovery lesson with their child. They were able to see first hand that calculators could be used for more than simple calculations. At the same time, other parents feared that while the calculator was a valuable tool, the discovery lesson took too much time and was not the best use of precious instruction time. While the general attitude of parents was favorable to the inclusion of the new technology into the curriculum, parents still feared that their children would not learn the basics or forget the benefits of doing math by hand (Sweeney).

Parental attitudes toward calculator usage have made a small shift forward over time. Research in the past decade revealed favorable attitudes toward the inclusion of the calculator into the classroom as they have witnessed many benefits. However, many of the same concerns have remained over time. In general, parents are concerned that their students will not be able to do mental computation or have a strong conceptual understanding of mathematics if they become dependent on the calculator.

Educational Organizations (Including State Boards of Education) In response to the growing popularity and availability of calculators, The National Advisory 
Committee on Mathematics Education (NACOME) published a history of mathematics education prior to 1975 and predicted the implications of calculators for the future (Conference Board of the Mathematical Sciences, 1975). NACOME noticed that calculators and computers were very popular in business and professional spheres, but not in schools. Students had difficulty understanding why they weren't allowed to use them. The committee recommended a number of changes to American mathematics education including the addition of the calculator as a tool for problem solving. Specific educational reforms to curriculum were mentioned to strengthen the effects of calculators in classrooms. Notably, NACOME recommended that all students from eighth grade and beyond have access to calculators for all class work and tests ("Math in the schools: What's wrong?", 1975). Shortly after NACOME's publication, the 1977-1978 National Assessment of Educational Progress (NAEP) mathematics assessment was published. The NAEP recommended the use of calculators to help improve computational deficiencies among American students.

In 1986, Connecticut was the first school to require calculators on a state mandated test (Libov, 1986). Teachers were instructed on how to use the calculators and 35,000 eighth grades students were given calculators at the beginning of the school year. The Connecticut School Board wanted its students to spend more time solving complex problems and improving their estimation skills (Libov, 1985). They reassured the public that students would still be taught the fundamentals of mathematics so that they would not rely too heavily on the new tool (Libov, 1986). Following on the heels of Connecticut, the Chicago Public School System gave out free calculators to all students aged fourth grade and older in 1988 ("Chicago Provides Free Calculators to Students," 
1988). Teachers were still required to teach multiplication facts without the use of a calculator, but students would now be free to solve more complex and challenging problems. At the end of the year, testing results showed improvement, except for the seventh grade ("Follow Up On The News: Free Calculators For Chicago Pupils," 1988). The State of Iowa was also concerned about the use of calculators on their state tests. Ansley, Spratt, \& Robert (1989) studied the use of a calculator on the Iowa Tests of Educational Development. The studied showed that students with a calculator performed slightly better than those without. Yet, the results were not significant.

In 1991, The New York Regents exam had a required calculator component to the test for the first time (Klutch, 1991). However, not everyone was on board with this decision. Opponents claimed that using calculators did not help students learn how to solve problems, but only get the right answer. Teachers felt that students were still lacking number sense. Yet, in 1992, the New York State Education Department allowed calculators to be used on the entire Regents' exam and no longer required students to show work on the test. Shortly after, New Jersey enacted the same policy and spent 1.5 million dollars to provide calculators for its students ("Calculators Allowed For Math Regents," 1992).

In 1989, The National Research Council published Everybody Counts: A Report to the Nation on the Future of Mathematics. It reiterated the importance of mathematics to the future of America as well as technology such as calculators and computers. The report claimed that one of the biggest challenges was the prevalence and power of calculators, yet the little impact they were having on education. They believed that calculators should be used to encourage student exploration, increase student motivation, 
and promote further levels of mathematical learning. Lastly, the report recommended that textbooks and curriculums begin to change to incorporate calculators (National Research Council, 1989).

The next wave of policy changes due to increased calculator use involved college entrance exams and classes taken for college credit. In 1983 and 1984, the College Board allowed calculators to be used on the Advanced (AP) Calculus exam (Greenes \& Rigol, 1992). But, after these two years, the College Board cancelled this allowance due to unfairness to students without a calculator. From 1991 to 1994, the College Board made changes to the tests to allow technology. In 1993, scientific calculators were required on the exam (Greenes \& Rigol). In 1997, Sandra Hinerman published a study on effects of calculators on the AP Calculus exam. On the portion of the test covering integrals, area, and volume, significant differences between the calculator groups and non calculator groups were seen. However, on the other portions of the tests, effects of calculator usage were not found.

The College Board also began to make changes to the SAT in 1990 (Greenes \& Rigol, 1992). However, the changes did not officially occur on the test until 1994. The 1994 test now included a number of student-produced response (SPR) questions. The SPR questions allowed for more reliable statistics, the elimination of student guessing, and the potential for questions to have more than one correct answer. The 1994 SAT also allowed students to use calculators on the exam. The SAT credits these changes to the influence of the NCTM and their desire for students to solve more realistic mathematical problems. At this time, unrealistic word problems were also put to an end (Lawrence et al., 2002). Scheuneman, Camara, Cascaller, Wendler, and Lawrence (2002) studied the 
recent changes to the SAT in the November 1996 and November 1997 SATs. Over 200,000 students were surveyed while taking the exam. In $1994,87 \%$ of students brought calculators to the exam, but after the 1997 exam, 95\% of student brought a calculator. Also, from 1996 to 1997, more students brought graphing calculators with them. Although calculators were prevalent, students used the device on less than half of the questions. Yet, those who used a calculator performed better than those who did not. Gender and ethnic differences were also found. Girls used calculators more than boys and Caucasian and Asian Americans used calculators more than Hispanic and African Americans (Scheunemna, et al.).

The Nation's Report Card: Mathematics 2000, (2001), published by The U.S. Department of Education, summarized the state of mathematics classrooms across the nation with specific attention paid to calculator usage. The report found that there was a decline in the number of students that used a calculator daily from 2000 to 1996 . Yet, in twelfth grade, increased calculator use correlated to increased test scores. Additionally, unrestricted use of calculators in eighth grade led to higher test scores than students with limited use (U.S. Department of Education, xvii). It was also found that calculator usage increased from 1996 and 2000 and that "more frequent use of calculators was associated with higher scores at grade 12 [and 8],” (U.S. Department of Education, 162-163).

In 2001, calculator policies still were not standardized. Educational Testing Services (ETS) allowed students to bring their own calculator to tests while the NAEP required students to use a standard issue calculator (Hanson, Brown, Levine, Garcia, 2001). Researchers set out to determine if the type of calculator used on a test made a difference. Fifty eight students from ethnically diverse backgrounds participated in the 
study. It was concluded that using a personal or standard issue calculator did not affect a student's accuracy, timing, number of keystrokes, level of confidence, or ease of calculator use. Yet, if the standard issue was more complex than the students own calculator they would chose to use the standard issue. Otherwise, students preferred their own (Hanson, Brown, Levine, Garcia).

A number of educational organizations have been involved in the calculator debate since 1975, as many have a vested stake in the fate of our students. Policy changes by state departments of education, college boards, and government run organizations have shared their opinions and sanctions over time. Most have tried to standardize the usage of calculators, particularly on exams in order to make testing fair to all students, regardless of their background. Yet, unanimous rulings have not been agreed upon.

Educators Teachers have felt the effects of the opinions and mandates from the NCTM, parents, and educational organizations as they sought to make changes in their own classrooms. Their teaching practices were deeply affected by the opinions of parents, administrator, and legislation as well as their own philosophies and opinions. From the very beginning of their popularity, many teachers insisted on using calculators in their classroom (Pendleton, 1975). Teachers were on the forefront of seeing students' increased motivation and desire to learn when they were permitted to use a calculator. At this time, teachers believed that students should be taught the basics before using a calculator on more realistic problems with bigger numbers (Pendelton). Yet, initial reactions to the calculator were not all positive. Other teachers were not willing to use calculators with their students because the effects had not been thoroughly researched 
yet. They believed that curriculum should be changed before introducing the new technology. A survey done by Mathematics Teacher found that $72 \%$ of teachers and laymen did not $7^{\text {th }}$ grade students using calculators (Pendelton). These teachers shared concern about an inability to help students understand and discover their errors because the calculators did not keep a log of the buttons that students were pushing. Teachers were unable to see and correct where the errors were coming from (Kiehl \& Harper, 1979).

The early days of this new technology revealed a striking inconsistency among teachers. A study by Wyatt, Rybolt, Reyes, and Bestgen (1979) revealed that $84 \%$ of teachers wanted to use calculators in their classrooms. However, only $3 \%$ of these teachers were employed by schools that gave them calculators to use. Teachers were untrained on how to use them. Teachers needed support from administration and parents if they wanted to bring the devices to their classrooms. None of these teachers worked in schools with a policy for calculator usage (Wyatt et al.). In 1994, many school districts still did not have policies regarding calculator use, but this did not stop teachers from using them (Ostaoczuk).

The debate among teachers continued into the 1980s and early 1990s. As previously described, the 1980s were characterized by increasing research and changes in the classroom. By 1982, practically every student had a calculator available to them at home (Seitz \& Parks, 1982). There were two major groups of teachers at this time: teachers who felt calculators hindered the acquisition of basic skills and teachers who believed the calculator was a necessary tool for the future that must be taught (Seitz \& Parks). There were also those who knew that the calculator mustn't be ignored, but felt 
strongly that teachers needed to show students how to use good judgment with a calculator (Willoughby, 1985). They believed students should use the calculator to solve complex problems, not simple mental math. They should use the calculator to solve problems that are interesting, understanding that calculators can only do what humans have designed them to do.

Though research was beginning to emerge in support of calculators aiding computational skills for students, $47 \%$ of students were still not permitted to use calculators on assessments (Roberts, 1980). Teachers who chose not to fully embrace the calculator cited reasons such as: the non-allowance of calculators on standardized tests such as the SAT or ACT, the lack of algebraic knowledge that students will gain, and the impediment of future mathematical studies due to reliance on calculators, among others (McConnell, 1988). Diane Hunskaer (1997) was another educator that did not support the use of calculators. In her experience and observations, she found that students who used calculators often were less able to problem love on their on. They were unable to think logically and clearly about mathematical processes. She also found that students struggled to generate strategies on their own for solving problems and then computing the answers.

Gary Bitter (1980) created a two hour workshop for teachers to attend that showed them how to use pocket calculators in their instruction and measured the teachers' attitude before and after the workshop. He found that the training made significant increases in teachers' attitudes toward using a calculator. The training helped teachers know how to effectively use the calculator for instruction and application in their own classrooms (Bitter). In addition to general teacher training, using calculators 
specifically designed to meet classroom needs raised teacher attitudes. At the end of a two year study on the Math Explorer Calculator teacher attitudes became more favorable by $20 \%$. There was unanimous agreement that calculators make math more fun for students and that the device should be a normal part of math classrooms (Bitter \& Hattfield, 1993).

Individual teachers were also quick to publish and praise their successes with calculators (Imerzeel, 1986). Though it took additional time for teachers to plan and incorporate the calculator into their classrooms, they claimed that it was worth it. Students were able to transfer their knowledge of general mathematics to specific problems, solve problems that were interesting to them, and take ownership of their learning (Imerzeel). Joseph Mercer also made calculators foundational in his classroom (1992). He wanted his students to be analytical thinkers, not students doing repetitious problems by hand. His goal was for students to think logically about mathematics and be able to communicate it well instead of memorizing algorithms. For teachers that did endorse the calculator, they found it difficult to convince parents and administrators that calculators could be used to enhance education and problem solving instead of only for solving simple computations (Bright, Lamphere, and Usnick, 1992).

Sarah Jeanne Hollister Davis was also a trend setter for her district. She worked with other science and history teachers to make unit plans that incorporated the graphing calculator. She emphasized the extra amount of time that it took to attend workshops and generate projects for her students, but stated that it was certainly worth it (Hollster Davis, 1997). On a very practical level, Marcia Tress (1998) used calculators in her Michigan classroom to teach students how to incorporate calculators into their daily life. She 
taught them how to pay taxes, bills, credit cards, and balance a checkbook. The major benefit of this style of teaching was that the calculator added value to her curriculum without detracting from it.

Another area of concern for teachers both for and against calculator use was the issue of timing (Fleener, 1995). When should calculators be introduced into the curriculum? Should students master a topic by hand in the classroom before being permitted to use a calculator? Or, should calculators be used to help students understand and learn a new concept? Of the 78 pre-service teachers surveyed, $55 \%$ felt that students must master a concept before using technology. A similar percentage of classroom teachers felt the same way. Teachers who had been teaching for long periods of time felt very strongly about this policy of waiting for mastery (Fleener).

By the 1990s, the calculator was clearly here to stay and the Graphing Calculator Epoch was among us. Teachers now had a complex machine to use in their classroom and were pressured to do so (Barrett \& Goebel, 1990). The graphing calculator gave teachers new techniques for solving equations, graphing, converting rectangular to polar graphs, store data, and analyzing functions. It was now much easier to solve realistic problems (Gunstein \& Lipsey, 1991). By the end of the decade, teachers were in agreement that graphing calculators promoted higher level thinking and questioning (Burrill, 2002). Teachers were showing students how to use the calculator and think through problems on their own, hopefully, without becoming dependent. Showing them how to use the calculator minimized misuse and error, as well as exposing its limitations. The benefits of using a graphing calculator for students included: increased ability to 
solve problems graphically, more frequent student exploration of mathematical concepts, and additional use of tools and methods to solve problems (Burrill, 2002).

The onset of graphing calculators made it very clear that teachers needed more training if they were to utilize the advanced technology (Burrill, 1992). It took a lot of time and patience for a teacher to be able to incorporate new techniques and activities with the device. Middle school teachers were beginning to use the calculators as well to solve problems of distance and rate and maximizing volume (Taylor \& Nichols, 1994). Teachers from 52 districts participated in Milou's (1998) study and requested training to show them how to teach with the calculator as they admitted their lack of understanding.

Laumarkis and Herman conducted a study that would give high school teachers in Florida an opportunity to receive specific instruction on using the TI-83 Plus calculator in their classroom. At the end of the training on pedagogical ideas, specific skills, linear functions, graphical representations, polygons, and transformations their students took the Florida Comprehensive Assessment Test. Their students performed better on the test than students who learned under teachers without the training (2006). In 2008, a one year professional development course was developed by Chamblee, Slough, and Wunsch for 22 high school math and science teachers with an emphasis on incorporating the graphing calculator into curriculum. By the end of the year, teachers had increased knowledge of the graphing calculator itself, ability to explore the technology, and ability to implement it in their classrooms. They were also prepared to teach specific skills with the technology.

Research on the individual teaching philosophies of teachers was also found to affect the use of technology in the classroom. Elaine Simmt (1997) conducted a case 
study of six high school teachers. She found that all of the teachers used graphing calculators in their classrooms, but the extent and depth of their use varied. Some teachers had their students use the graphing calculators to check their answers. Others extended the topic at hand to teach beyond the basics. Still, other teachers showed the limitations of the calculator. Additionally, teachers used the graphing calculators to have their students discover topics on their own. A similar philosophy between all of the teachers was the belief that mathematics is logical and sequential. They agreed that students should be shown how concepts fit together and relate.

However, the differences in their teaching styles were correlated to differing philosophies. Some teachers were focused on teaching how mathematics is a set of rules to be followed, while other teachers focused on assuring students that they could learn math. Their approval of graphing calculators varied and a few were cautions to change the curriculum to encompass it.

Another study of 816 teachers of grades K-12, found a number of connections between beliefs of teachers and their practices (Brown et al., 2007). First, teachers of all grades believed that their students were more interested and engaged when using a calculator. All of the teachers also agreed that students' learning improved with the device, but still wanted students to show their work. Lastly, classroom inequalities did not seem to exist between students who had access to calculators at home and those who did not (Brown et al.). There were also a number of beliefs categorized by grade. High school teachers used the calculators often in their classrooms, but not as a replacement for learning procedures and facts. Algebra 2 teachers were also more likely than Algebra 1 teachers to utilize the technology (Milou, 1998). Algebra teachers wanted concepts 
mastered first before using the calculator. Middle school teachers used the calculator with limitations. They believed that students should master a concept first before using or use it to check their work. Elementary teachers had the greatest difficulty balancing the device in their classroom (Brown et al).

The latest development in calculators used in education is the TI-Navigator. With a classroom set of these calculators, teachers are able to transmit questions and receive answers and data from their students while connected to a computer. Teachers can use this system for quick quizzes and up to date feedback on how well students understand. Teachers find it easier to adapt and change lesson plans while using this program (Cavanagh, 2006).

Educators are most impacted day to day by calculator policy and usage. Their curriculum is ever changing based on the technology. From the beginning, most teachers have been on board with the addition of the calculator to their classrooms. Yet, concerns still loomed. Though many of the concerns have been researched, they still remain. Teachers still struggle with the balance or knowing when to incorporate the calculator? Should it be used as a learning tool or a tool to be used after mastery? Also, to what extent should the calculator be used? Should it be used throughout the class time or just for certain portions? Will students forget the basics of their mathematical understanding and become dependent on the technology. Though progress has been made, not all questions have been answered for teachers. 


\section{Summary}

The NCTM, parents, educators, and other educational organizations have all been affected by the emergence of the calculator. At different periods of time, each of these groups has been leaders and followers in the changes to our educational system.

Research has helped to push forward and draw back our student from technology. Each group has gone through many changes in attitude over the past four decades. They have moved forward in widespread acceptance of the calculator and then moved taken steps backwards to rethink and replan. Each group has had the best interest of students in mind, but the answers have not always been clear. The ebb and flow of the calculator debate continues. 


\section{Discussion and Implications Results \& Analysis}

\section{Introduction}

This study was conducted in order to analyze the changes of attitudes and opinions of parents, educators, and national organizations in America since 1975 pertaining to calculator usage in junior high and high school students. Attention was paid to the major historical events, legislation, and policy changes that potentially led to changes in these attitudes. The effects that each of these events had on educators, parents, and educational organizations were considered. This chapter will examine the results of the findings based on historical analysis, potential applications of the findings, the strengths and limitations of the study, as well as suggestions for future research.

\section{Interpretations of the Results}

History is a valuable resource if we chose to learn from it. Educational organizations, parents, legislators, and teachers can all learn from this study and its many implications. It is useful for consideration when generating school wide policies for calculator usage, changes to standardized or state mandates tests, as well as personal opinions about the issue.

The analysis from chapter four showed four major findings. First, the NCTM has been leading the way since 1978 in pushing educators to incorporate calculators into their classrooms and sanctioning that students have access to calculators their entire school career. They clarified their position as time wore on to remind educators the importance of teaching students when using a calculator is the best idea, as opposed to mental math 
or paper and pencil methods. Yet, they have remained unwavering in their belief that calculators must be used to help students learn better in math class.

Other educational organizations have followed closely the position of the NCTM. Government research organizations have repeatedly urged educators to use calculators often in their classroom, starting with young students. State boards of education and school district officials have continued to push calculator usage to greater popularity by requiring them to be used on state mandated tests and giving away free calculators to all students. The increased allowance and requirement on college entrance exams have increased popularity as well.

The third group considered was educators, as they were required to implement the opinions of national organizations and their individual school boards. Educators have been quick to agree that calculators make math fun and more motivating for students. Yet, in the day to day teaching, teachers have raised many concerns about the calculator. They still fear that their students will not learn or remember the basics or be able to think about mathematics as a logical whole as they grow older. Teachers have not wanted their students to become dependent on calculators.

Finally, parents have been very interested in their children's mathematics education, particularly in the area of their futures. Parents have been very excited about the potential of the calculators and the increased motivation seen in their children. Yet, many parents are still greatly concerned over their children's lack of arithmetic skills and critical thinking abilities due to dependence on the calculator.

When comparing these groups, two other interpretations surface. First, the NCTM and other educational organizations have led the way for increased calculator use. 
Their research has aligned with one anther's and similar conclusions have been drawn. It has been their sanctions that have altered mathematics curriculum. Their push forward for increased technology has resulted from their look at a bigger picture of education in America. They foresaw where the American educational system was lacking and how it needed to move forward. Then, they created statements and policies to push Americans toward it. These organizations have been very clear in their support of the new technology and pushed this view on many others.

Second, parents and educators, together, have been more reserved in the day to day administration of calculator usage. They have witnessed drawbacks to the technology and have not pushed calculator usage as far. Parents and educators are seeing individual students at work and the effects the calculator are having on them. Unlike educational organizations, parents and educators are concerned about specific students, not American students as a whole. Parents and educators are also given the difficult task of practically implementing the decisions and policies of educational organizations. This may explain why their opinions have been more reserved.

As a whole, the American educational system since 1975 has warmly embraced the use of calculators in our school system. They are now seen in nearly every classroom across the country and teachers are being trained on how to implement them. Since they were easily accessible for most American families, our teaching methodologies and curriculums have been altered to include them. Although parents and teachers have presented concerns over time, calculators still remain prominent. These concerns have not put an end toward the usage of calculators, but rather impacted the way that this new technology is practically used in classrooms. All four major groups agree the calculators 
increase motivation and desire to learn among students and should be used on a regular basis. It is the implementation of calculator usage that remains up for debate among these groups.

\section{Potential Applications of the Findings}

This study provides potentially significant application for parents, educators, and educational organizations if they consider it. Parents can better understand how to be more involved and proactive in their children's mathematics education. Teachers can be better prepared to make curriculum decisions for their classrooms on whether to include calculators into their lessons or not. Educational organizations can be aware of how to the past has affected their current policies and how to make wise decisions regarding new policies in the future. School boards can be better prepared to make informed decisions regarding district wide policies. Each group can use the analysis in this study for their future.

The first application on this study involves understanding the importance of historical events and changes in the past. The past always affects the present and the future. It may be even be used as a predictive measure for the future. Understanding the background of calculator usage and the changes in attitudes towards it since 1975 will help us understand the present. It can help us understand the current dilemmas, debates, and problems in mathematics classrooms across the nation. Parents and teachers can understand what parts of this history have been controversial and what effects the controversy has had on policy decision. National organizations and legislators can look back at their decisions and understand the implications that followed. 
Next, an understanding of the history of calculators and the attitudes toward them helps educators understand the changes in calculator usage over the past few decades. They will be able to understand how our school systems have arrived at their current policies. Teachers will be able to see that it has not been an easy road to travel or one taken lightly to reach current positions. This study will also allow teachers to see what historical events have impacted classrooms in the past to understand how current debates have the potential to impact their current classrooms. With more information, educators will be able to examine how they want to change policies and attitudes for the schools in the future.

This study also helps educators and school district administrators examine continual themes of concern since 1975. Many of the apprehensions that were presented at the onset of popular calculator usage are still concerns today. Though culture and times have changed, many issues still exist. Teachers can use the policies of the past and principles followed and evaluate the appropriateness of them in classrooms today. Understanding concerns that prevailed for decades will help teachers maintain perspective today.

Lastly, this study is a reminder that calculator usage is more than a right or wrong issue. Parents, teachers, and educators are not debating if calculators should be used. Rather, they are trying to understand how using calculators effects students in the long run. They attempt to predict how changes in policy will effect students once they leave the educational setting and become contributing members in society. This study prompts educators to consider the importance of their attitudes and the decisions that result because of them. 
In the future, there is no doubt that calculators will remain important, yet debatable part of mathematics education. Parents, educators, and organizations alike boast of the calculators many benefits to students. Parents want their children to receive a high quality education that includes the latest technology that will prepare them for life outside of the classroom. Parents will continue to want calculators to be an integral part of their child's learning, even though they have concerns. Educators will continue to receive training in order to be better prepared for teaching with the calculator particularly in regards to standardized tests that require their use. Their textbooks and curriculum will continue to be altered to include the latest developments in calculator technology. The TI-Navigator and other similar systems will grow in prominence as they provide immediate feedback for teachers to generate higher quality lessons. National organizations will continue to offer training and advice for teachers in the field. Their resources will be used continue increased use in calculators in classrooms. While application of calculators into the classroom will change over time, the issue of calculators will not.

\section{Strengths of the Study}

This study is the first formal collection of documentation of the historical events and attitudes of parents, teachers, and educators in the area of calculator usage since 1975. Histories of calculators and their use in schools have been written in the last decades. However, these did not explore and investigate the changes of attitudes in regards to calculator usage over time. Comparisons have not been drawn between various groups either. 
Another strength of this study is its balance of research and comprehensive nature. This paper includes academic research from various sources. Yet, it also holds articles from popular newspapers and publications, including opinion columns and letters to the editor. A variety of sources and opinions were put together to form a more cohesive perspective. Teachers, tutors, parents, organizational leaders, legislators, and other voices were presented here. These are men and women on the front lines of education witnessing the daily effects of calculators on students. Their perspectives are important to understanding how and why calculator policies have changed.

\section{Limitations of the Study}

First, the time period of this study was limited. Research from this study was gathered from 1975 until the present day. Research prior to this point was not considered. Prior to 1975 , calculators were not readily available to the average American. Thus, they were not prominent in school settings.

Another limitation of the study was the nature of its broad overview. Analysis and specification of the changes through each category, parents, educators, the NCTM, and other national organizations, could have been analyzed further and possibly each into their own paper. However, the purpose of this study was to provide a comprehensive overview of the changes in attitudes toward calculator usage, not a detailed examination. A more narrow focus on each of these groups has the potential for additional papers.

This study only compared research and opinions for educators, parents, and organizations working with junior high and high school students. Additional research regarding younger children was not utilized. Additionally, data collected from private 
schools or classrooms focusing on students with special needs was also not used. The purpose of this study was a broad overview of calculators in public, mainstream, junior high and high school classroom. Therefore, results and analysis may have differed if these additional populations were included.

The attitudes and opinions of students were not considered in this area. Many other studies since 1975 have focused solely on how students felt about calculator usage in their classrooms. This was outside of the original research question and greatly researched by other scholars. Studies such as Ellington's (2003) and the 54 studies that it is a meta-analysis of would be a useful resource for understanding the student perspective.

\section{Suggestions for Future Research}

As the first study of this kind on the changes of attitudes toward calculator use, it is an important beginning to understanding the development of calculator usage in America since 1975. Further research and analysis on the following topic could add to depth of this study.

Additional research on each era of calculator history would beneficial and lead to greater understanding. More detailed study of each of the 10-15 year eras would bring out more particulars from each time period. A study could be done on each era and the changes that occurred within the shorter time period. This detailed analysis was not possible for an examination of over four decades.

A similar historical study on the changes and attitudes of elementary school teacher, parents, and educators would also be interesting. Understanding younger 
students would help made more sense of the attitudes and actions of older students. The conditions that elementary school children learned under certainly effects the classrooms of junior high and high school classrooms and ultimately their teachers and parents attitudes and opinions.

The present study also provides the basis for further study in the following areas: (1) At what point in the curriculum should calculators be introduced to students? Should students master the concept by hand before using the technology, or not? (2) How have school curriculums changed for teachers to use since the NCTM's sanctions for increased calculator usage? (3) How have calculators helped or hindered students' retention of mathematical knowledge and processes over time? (4) How have entire school districts prepared their teachers for the changes in mathematics due to calculators? What trainings have they found beneficial in the long run?

The possibilities for further research on calculators, their usage, and educator's opinions of them are nearly limitless. Each additional study would add depth and vividness to understanding the effects on the students in America. It would help parents, educators, and national educational organizations with necessary information make informed changes to improve the educational system for the future. 


\section{References}

About ETS. (2009). Retrieved December 1, 2009 from www.ets.org/about

ACT. (2010). Retrieved May 11, 2010 from http://www.act.org/aap/

Ansley, T.N., Spratt, K.F., \& Forsyth, R.A. (1989). The effects of using calculators to reduce the computational burden on a standardized test of mathematics problem solving. Educational and Psychological Measurement, 49, 277-286.

Barrett, G. \& Goebel, J. (1990). The impact of graphing calculators on the teaching and learning of mathematics. In T. Cooney (Ed.) Teaching \& Learning Mathematics in the 1990s. Reston, VA: National Council of Teachers of Mathematics.

Berg, B.L. (2001). Qualitative research methods for the social sciences (4ed.). Boston: Pearson Education Company.

Bernklau, D. (1990, December 29). Calculator has become invaluable tool. [Letter to the editor]. New York Times, p22.

Bitter, G.G. (1980). Calculator teacher attitudes improved through inservice education. School Science and Mathematics, 80, 323-326.

Bitter, G.G. \& Hatfield, M.M. (1993). Integration of the Math Explorer calculator curriculum: The calculator project report. Journal of Computers and Science Teaching, 12, 59-81.

Branca, N.A., Breedlove, B.A., \& King, B.W. (1992). Calculators in the middle grades: Access to rich mathematics. In J. Fey (Ed.) Calculators in Mathematics Education. Reston, VA: The National Council of Teachers of Mathematics. 
Brown, E.T., Karp, K., Petrosko, J.M., Jones, J., Beswick,G., Howe, C.,\& Zwanzig, K. (2007). Crutch or catalyst: Teachers' beliefs and practices regarding calculator use in mathematics instruction. Journal of School Science and Mathematics, 107, 102-116.

Bright, G.W., Lamphere, P.L., \& Usnick, V.E. (1992). Statewide in-service programs on calculators in mathematics teaching. In J. Fey (Ed.) Calculators in Mathematics Education. Reston, VA: The National Council of Teachers of Mathematics.

Burrill, G. (1992). The graphing calculators: A tool for change. In J. Fey (Ed.) Calculators in Mathematics Education. Reston, VA: The National Council of Teachers of Mathematics.

Burrill, G., Allison, J., Breaux, G., Kastberg, S., Leathman, K., \& Sanchez, W. (2002). Handheld graphing technology in secondary mathematics: Research findings and implications for classroom practice. Dallas, TX: Texas Instruments.

Calculators allowed for math regents. (1992, August 8). New York Times. Retrieved March 4, 2011, from http://nytimes.com

Calculators OK in Math. (2008). The Science Teacher. 22-24.

Cavanagh, S. (2006, November 15). Technology helps teachers home in on student needs. Education Week, 26, 10-11. Retrieved November 7, 2009 from Academic Research Complete database.

Chamberlee, G.E., Slough, S.W., \& Wunsch, G. (2008). Measuring High School Mathematics Teachers' concerns about graphing calculators and change: A yearlong study. Journal of Computers in Mathematics and Science Teaching, 27, 183-194. 
Chicago provides free calculators to students. (1988, January 5). New York Times.

Retrieved March 4, 2011, from http://nytimes.com

Conference Board of the Mathematical Sciences. (1975). Overview and analysis of school mathematics, grades $K-12$. Washington: The Board.

Clayton, M. (1999, November 9). The calculator effect. Christian Science Monitor. Retrieved March 4, 2011 from http://www.csmonitor.com

Conrad, C.F., \& Serlin, R.C. (2006). The SAGE handbook for research in education: Engaging ideas and enriching inquiry. Thousand Oaks, CA: SAGE Publications, Inc.

Ellington, A. J. (2003). A meta-analysis of the effects of calculators on students' achievement and attitude levels in precollege mathematics classes. Journal for Research in Mathematics Education, 34, 433-463.

Ellington, A.J. (2006). The effects of non-CAS graphing calculators on student achievement and attitude levels in mathematics: A meta-analysis. Journal of School Science and Mathematics, 106, 16-26.

Fleener, M.J. (1995). The relationship between experience and philosophical orientation: A comparison of preservice and practicing teachers' beliefs about calculators. Journal of Computers in Mathematics and Science Teaching, 14, 259-376.

Follow-up on the news; Free calculators for Chicago pupils. (1988, November 13). New York Times. Retrieved March 4, 2011, from http://nytimes.com Gelernter, D. (1998). Kick calculators out of class. The Reader's Digest, 918, 136-137. Gleick, J. (1987, November 8). New directions; The hand-held calculus. New York Times. Retrieved March 3, 2011, from http://nytimes.com 
Greenes, C.E., Rigol, G.W. (1992). The use of calculators on College Board standardized tests. In J. Fey (Ed.) Calculators in Mathematics Education. Reston, VA: The National Council of Teachers of Mathematics.

Gunstein, L.S., Lipsey, S.J. (Eds.). (2001). Encyclopedia of mathematics education. New York: RoutledgeFalmer.

Guthrie, J.W. (Ed). (2003). Encyclopedia of Education (2 ${ }^{\text {nd }}$ ed., Vol 1-8). New York: Macmillan.

Hanson, K., Brown, B., Levine, R., Garcia, T. (2001). Should standard calculators be provided in testing situations? An investigation of performance and preference differences. Applied Measurement in Education, 14, 59-72.

Hechinger, J. (2006, September 12). New Report Urges Return to Basics In Teaching Math. Wall Street Journal-Eastern Edition, 248, A1.

Heinerman, S.D. (1997). Graphing calculators in the Calculus classroom. Unpublished Master's thesis, Salem-Teikyo University.

Hollister Davis, S.J. (1997). How mastering technology can transform math class.

Educational Leadership: Association for Supervision and Curriculum Development, 55, 49-52.

Hunsaker, D. (1997). Ditch the calculators. Newsweek. 130, 20.

Immerzeel, G. (1986). It is 1986 and every student has a calculator. Instructor. 85, 24-51, 148.

Jeehlen, A. (2001). Calculators in the classroom. NEA Today, 19, 24-26.

Kiehl, C.F. \& Harpher, B.A. (1979). My child the math whiz??? Or buy your child a calculator. Education, 100, 18-19. 
Klutch, R.J. (1991, September 29). The calculator crutch. New York Times. Retrieved March 4, 2011, from http://nytimes.com

Laumakis, P., Herman, M. (2008). The effect of a calculator training workshop for high school teachers on their student's performance on Florida state-wide assessments. International Journal for Technology in Mathematics Education, 15, 87-93.

Laursen, K.W. (1978). Use of calculators in high school general mathematics: A study comparing achievement, attitude, and attendance of general mathematics students who used a calculator and those who did not. (Doctoral dissertation, Brigham Young University, 1978). Dissertation Abstracts International, 39A, 733.

Lawrence, I., Rigol, G.W., Van Essen, T., \& Jackson, C.A. (2002). A historical perspective on the SAT 1926-2001. New York, NY: College Entrance Exam Board.

Lawton, M. (1997). Calif. education officials approve back-to-basics standards in math. Education Week, 17, 6.

Lawton, M. \& Hoff, D.J. (1997). Riley delays national tests' development. Education Week, 17.

Lee, J. (1999, September 2). Calculators throw teachers a new curve. New York Times. Retrieved March 3, 2011, from http://nytimes.com

Libov, C. (1985, December 8). Calculators in exam debated. New York Times. Retrieved March 3, 2011, from http://nytimes.com

Libov, C. (1986, August 31). State adding a tool for $8^{\text {th }}$ grade math. New York Times. Retrieved March 3, 2011, from http://nytimes.com 
Marshall, C., \& Rossman, G.B. (2006). Designing Qualitative Research (4 ed.). Thousand Oaks, CA: SAGE Publications, Inc.

Mason, J. (2002). Qualitative Researching (2ed.). London: SAGE Publications, Inc.

"Math standards". (1989). Education Digest, 54, 64.

"Math in the schools: What's wrong?". (1975). Science News, 108, 325.

"Mathematics teachers urge course reform". (1980). Science News, 177, 247.

McConnell, J.W.(1988). Technology and Algebra. In A. Coxford (Ed.), The ides of algebra, K-12. (pp.142-148). Reston, VA: The National Council of Teachers of Mathematics.

Mercer, J. (1992). What is left to teacher if students can you calculators?. The Mathematics Teacher, 85, 415-417.

Milou, E. (1998). Attitudes toward and use of the graphing calculator in the teaching of algebra. (Doctoral dissertation, Temple University, 1998). Dissertation Abstracts International, 59, 1956.

Milou, E. (1999). The graphing calculator: A survey of classroom usage. School Science and Mathematics, 99, 133-140.

Mission, vision, and priorities. (2009). Retrieved December 1, 2009, from http://www.nctm.org/ about/content.aspx?id=172

Morgan, R., \& Stevens, J. (1991). Experimental study of the effects of calculator use on the Advanced Placement Calculus examinations. Princeton, NJ: Educational Testing Services.

NAEP overview. (2009, August 6). Retrieved December 1, 2009 from http://nces.ed.gov/ nationsreportcard/about/ 
National Council of Teachers of Mathematics (1980). An agenda for action:

Recommendations for school mathematics of the 1980s. Reston, VA: NCTM.

National Council of Teachers of Mathematics (2005). Computation, calculators, and common sense: A position of the National Council of Teachers of Mathematics. Reston, VA: NCTM.

National Council of Teachers of Mathematics (1989). Curriculum and evaluation standards for school mathematics. Reston, VA: NCTM.

National Research Council (1989). Everyone counts: A report to the nation on the future of mathematics education. Washington DC: National Academy Press.

Ostapczuk, E. D. (1994) The status of hand held calculators in secondary mathematics: An examination of issues and uses in the classroom throughout the Mid-Hudson Valley region. Marist College. (ERIC Document Reproduction Service No. ED380410)

Pendelton, D. (1975). Calculators in the classroom. Science News, 107, 175-181.

Peterson, I. (1982, July 31). Can you count on your computer?. Science News, 122, $72-$ 75.

Peterson, S.J. (2006). Priming the historian in all planners. Journal of Planning History, 5, 289-300.

Protter, M.H. (1990, December 8). Calculators are wrong answer for S.A.T.'s. [Letter to the editor]. New York Times, p.24.

Quinn, D. R. (1976). Yes or No? Calculators in the Classroom. National Association of Secondary School Principals, 60, 77-80. 
Roberts, D. (1980). The impact of electronic calculators on educational performance. Review of Educational Research, 50, 71-98.

Rudnick, J., \& Krulik, S. (1976). The minicaclulator: friend or foe?. Arithmetic Teacher, 23, 654-656.

Ryan, W.F. (1999). The effects of using the TI-92 calculator to enhance junior high students' performance in and attitude toward geometry. (ERIC Document Reproduction Service No. ED436414)

Sandberg-Diment, E. ( 1986, November 25). Personal computers; Groundbreaker in math. New York Times. Retrieved March 4, 2011, from http://nytimes.com SAT. ( 2009). Retrieved December 1, 2009 from http://www.collegeboard.com/student/testing/ sat/about/SATI.html

Scheuneman, J.D., Camara, W.J., Cascallar, A.S., Wendler, C., Lawrence, I. (2002). Calculator access, use, and type in relation to performance on the SAT I: Reasoning test in mathematics. Applied Measurement in Education, 15, 95-112.

Seitz, S. \& Parks, T.E. (1982). Calculators in Schools: Thoughts and Suggestions: In S. Hill (Ed.), Education in the 80's: Mathematics. (pp.36-45). Washington DC: National Education Association.

Shapiro, D.T. (1999, September 9). The calculator as crutch [Letter to the editor]. The New York Times, p.4.

Simmt, E. (1997). Graphing calculators in high school mathematics. The Journal of Computers in Mathematics and Science, 16, 269-89. 
Suydam, M.N. (1982). Computation: Yesterday, today, and tomorrow. In S. Hill (Ed.), Education in the 80's: Mathematics. (pp.36-45). Washington DC: National Education Association.

Sweeney, S. (2004). Attitudes and beliefs of parents of middle school children about calculators in school mathematics. (Doctoral dissertation, The Ohio State University). Dissertation Abstracts International, 65, 2482.

Taylor, B.L., \& McKean, R.C. (1979). News notes: National Council of Teachers of Mathematics position statement on calculators. Educational Leadership, 36, 367368.

Taylor, L.J.C. \& Nichols, J.A. (1994). Graphing calculators aren’t just for high school students. Mathematics Teaching In The Middle School, 1, 190-196.

TI-83 Plus: Features summary. (2009). Retrieved December 1, 2009 from http://education.ti.com/educationportal/sites/US/productDetail/us_ti83p.html TI- Navigator: Features summary. (2009). Retrieved December 2, 2009 from http://education.ti.com/educationportal/sites/US/productDetail/us_ti_navigator.ht $\mathrm{ml}$

Tress, M. (1998). Visual Learners. Curriculum Administrator ,34, 24.

Trotter, A. (1991). Graphing calculators are coming to class. The Executive Educator, $13,20$.

U.S. Department of Education. Office of Educational Research and Improvement. National Center for Education Statistics. The Nation's Report Card: Mathematics 2000, NCES 2001-517, by J.S. Braswell, A.D. Lutkus, W.S. Grigg, S.L. Santapau, B.S.-H. Tay-Lim, and M.S. Johnson. Washington, DC: 2001. 
Vaugh, L. (1976). A problem of the effects of hand-held calculators and a specially designed curriculum on attitude toward mathematics, achievement in mathematics, and retention of mathematical skills.Unpublished doctoral dissertation, University of Houston.

Waits, B.K., \& Demana, F. (2000). Calculators in mathematics teaching and learning: Past, present, and future. In M. Burke (Ed.) Learning Mathematics for a New Century. Reston, VA: National Council of Teachers of Mathematics.

Webster's ninth new collegiate dictionary (9th ed.). (1988). Springfield, MA: MerriamWebster Inc.

Wildstrom, S.H. (1997, September 8). A math student's best friend. BusinessWeek, $3543,20$.

Willoughby, S. (1992). Trends: Mathematics: The use of calculators. Educational Leadership, 49, 87.

Willoughby, S. (October, 1985). Curriculum trends: Mathematics: Will calculators rot our minds?. Educational Leadership, 43, 90-91.

Wyatt, J.T, Tybolt, J.F., Reyes, R.E., and Bestgen, B.J. (1979). The status of hand-held calculator use in school. Phi Delta Kappan, 61, 217-218.

Wyche, S., Sengers, P., \& Grinter, R.E. (2006, May 9). Historical analysis: Using the past to design the future. Retrieved March 8, 2011, from http://www.cc.gatech.edu/ beki/c29.pdf 